\title{
AI versus Classic Methods in Modelling Isotopic Separation Processes: Efficiency Comparison
}

\author{
Vlad Mureșan ${ }^{1}$, Mihaela-Ligia Ungureșan ${ }^{2, *}{ }^{\mathbb{D}}$, Mihail Abrudean ${ }^{1}$, Honoriu Vălean ${ }^{1}$, Iulia Clitan ${ }^{1}$, \\ Roxana Motorga ${ }^{1}$, Emilian Ceuca ${ }^{3}$ and Marius Fișcă ${ }^{1}$ \\ 1 Automation Department, Technical University of Cluj-Napoca, 400114 Cluj-Napoca, Romania; \\ Vlad.Muresan@aut.utcluj.ro (V.M.); Mihai.Abrudean@aut.utcluj.ro (M.A.); \\ Honoriu.Valean@aut.utcluj.ro (H.V.); Iulia.Clitan@aut.utcluj.ro (I.C.); roxana_motorga@yahoo.com (R.M.); \\ mariusfisca@gmail.com (M.F.) \\ 2 Physics and Chemistry Department, Technical University of Cluj-Napoca, 400114 Cluj-Napoca, Romania \\ 3 Informatics, Mathematics and Electronics Department, "1 Decembrie 1918" University of Alba Iulia, \\ 510009 Alba Iulia, Romania; emilian.ceuca@uab.ro \\ * Correspondence: Mihaela.Unguresan@chem.utcluj.ro
}

Citation: Mureșan, V.; Ungureșan, M.-L.; Abrudean, M.; Vălean, H.; Clitan, I.; Motorga, R.; Ceuca, E.; Fișcă, M. AI versus Classic Methods in Modelling Isotopic Separation Processes: Efficiency Comparison. Mathematics 2021, 9, 3088. https:// doi.org/10.3390/math9233088

Academic Editor: Daniel-Ioan Curiac

Received: 14 October 2021

Accepted: 28 November 2021

Published: 30 November 2021

Publisher's Note: MDPI stays neutral with regard to jurisdictional claims in published maps and institutional affiliations.

Copyright: (C) 2021 by the authors. Licensee MDPI, Basel, Switzerland. This article is an open access article distributed under the terms and conditions of the Creative Commons Attribution (CC BY) license (https:// creativecommons.org/licenses/by/ $4.0 /)$.

\begin{abstract}
In the paper, the comparison between the efficiency of using artificial intelligence methods and the efficiency of using classical methods in modelling the industrial processes is made, considering as a case study the separation process of the ${ }^{18} \mathrm{O}$ isotope. Firstly, the behavior of the considered isotopic separation process is learned using neural networks. The comparison between the efficiency of these methods is highlighted by the simulations of the process model, using the mentioned modelling techniques. In this context, the final part of the paper presents the proposed model being simulated in different scenarios that can occur in practice, thus resulting in some interesting interpretations and conclusions. The paper proves the feasibility of using artificial intelligence methods for industrial processes modeling; the obtained models being intended for use in designing automatic control systems.
\end{abstract}

Keywords: separation cascade; modeling; efficiency; AI (artificial intelligence); neural network; ${ }^{18} \mathrm{O}$ isotope

\section{Introduction}

Most of the elements in nature consist of several atomic species referred to as isotopes. The isotopes have the same position in the periodic table, they have the same number of electrons, but they have a different number of neutrons. The isotopes can be stable when they are not disintegrating over time or radioactive when they are affected by the radioactive disintegration process. A measure of the atom's concentration of an isotope for a given element is represented through its natural abundance in mixture with other isotopes. For example, there are to be found three stable isotopes in nature for the oxygen element: ${ }^{16} \mathrm{O}(99.759 \%) ;{ }^{17} \mathrm{O}(0.037 \%)$, and ${ }^{18} \mathrm{O}(0.204 \%)$. The stable isotopes that are needed in different applications [1-6] can only be found in very small concentrations in nature, so justifying the need for increasing their concentration. Starting from the 1960s, due to the peaceful use of nuclear energy, the necessity of new nuclear fuels, and large-scale applications in different domains of tagged atoms, the implementation, at industrial scale, of the stable isotopes (namely, oxygen, nitrogen, carbon, boron, lithium, etc.) separation methods became an important target. Consequently, the stable isotopes have presented a great interest in the last years. As tagging elements, the isotopes have proved to be an extremely advantageous tool in several domains, such as: chemistry, biology, medicine, agriculture, etc. The study of the natural isotope abundances offers important information regarding the water circulation in the atmosphere or underground, the origin of the underground distribution of the hydrocarbon or even the rocks' age. The 
analysis of the isotopic composition of the meteorites represents a modern method for the space exploration. The ${ }^{18} \mathrm{O}$ isotope for the ${ }^{18} \mathrm{~F}$ production used in the positron emission tomography, respectively, the ${ }^{13} \mathrm{C}$ and ${ }^{14} \mathrm{C}$ isotopes, which are used in the respiratory tests, plays an important role in medicine nowadays. Another important domain in which the stable isotopes of ${ }^{18} \mathrm{O},{ }^{15} \mathrm{~N}$, and ${ }^{13} \mathrm{C}$ are used as tracer agents in agriculture [5], improving the usage of the chemical fertilizer. The most frequent stable isotopes separation methods use the distillation procedures of the compound that contains the followed isotope in liquid or in gaseous phase, respectively, the isotopic exchange in countercurrent on columns with packing. Isotopic separation methods are based on the existence of an elementary separation process, which is due to differences in physicochemical properties (mass, density, boiling temperature, etc.) of isotopic compounds and is numerically characterized by the elementary separation factor $\alpha$, which shows how many times the ratio of isotopic equilibrium concentrations in one of the reactants is higher than that corresponding one to the other reactant.

In the case of isotopic exchange reactions, the elementary separation factors have slightly different values than that of the unit value, for most light elements, except hydrogen. These results, after the elementary separation process, in an insufficient separation for applications, which makes it necessary to multiply the elementary separation factor $\alpha$. This multiplication can be achieved by means of the separation columns with packing or plates, in which the substances that change isotopes circulate in countercurrent or in uniflow, usually one in the liquid phase and the other one in the gaseous phase.

In the separation column, due to a transversal isotope transport between the two phases, an isotopic separation occurs at its ends; separation that depends on the flow rates, on the height of the column, and on $\alpha$ [1-3]. The equilibrium constants of the isotopic exchange reactions in which the isotopes of the light elements $H, B, C, N$, and $\mathrm{O}$ participate are slightly different from the value 1 . Usually, the isotope with the higher mass is concentrated in the reactant molecules with higher molecular weight, and the lower mass isotope in the molecules of the other reactant. The separation element is the smallest cell in an isotopic separation plant that achieves a separation equal to the elementary separation factor $\alpha$. It divides the supply current, having natural abundance, into two currents of different concentrations: the current, partially enriched, of the desired isotope having a certain concentration, and the partially diluted current having a different concentration. Since the separating element processes only a small amount of substance, in order to increase the processed amount, several elements are connected in parallel, which will be fed with material of the same isotopic concentration. Such a battery of elements forms a separating stage. In order to obtain high isotopic concentrations of the products extracted from the separation plant, several stages are connected in series forming a separation cascade.

The separation of the isotopes is carried out using separation columns with specific equipment having a complex structure and operation [7-14]. The separation columns are operated as a refluxing system, the pipes being positioned at the columns two edges. The refluxing systems are used to restore the separated isotope into the separation column (the refluxing system from the base of the separation column converts the separated isotope from the liquid phase to the gaseous phase and returns it into the separation column; the reflux system from the separation column top converts the separated isotope from the gaseous phase into the liquid phase and is also re-entered into the separation column). The processes associated to the separation columns represent a distributed parameter MIMO (Multiple Input Multiple Output) technological processes having a nonlinear behavior. Consequently, the complexity of the separation processes explains the fact that their modeling and control are challenging in the field of automation. Another important aspect to be considered is the costs of the production of isotopes. In this context, the improvement of the separation plants energy consumption efficiency becomes a main objective. 
In this paper, the usage of a separation cascade, containing on its structure two separation columns, is considered for the practical implementation of the separation procedure through the system $\mathrm{NO}, \mathrm{NO}_{2}-\mathrm{H}_{2} \mathrm{O}, \mathrm{HNO}_{3}[6,14-19]$. This procedure is used for the separation of the ${ }^{18} \mathrm{O}$ isotope. In the case of using the system $\mathrm{NO}, \mathrm{NO}_{2}-\mathrm{H}_{2} \mathrm{O}, \mathrm{HNO}_{3}$ as the separation procedure, the nitric oxides circulate in countercurrent with the nitric acid solution, the isotopic exchange being made after the following equation:

$$
\mathrm{N}^{16} \mathrm{O}+\mathrm{H}_{2}{ }^{18} \mathrm{O} \stackrel{\mathrm{HNO}_{3}}{\leftrightarrow} \mathrm{N}^{18} \mathrm{O}+\mathrm{H}_{2}{ }^{16} \mathrm{O}
$$

with a single stage separation factor of 1.018 at $25{ }^{\circ} \mathrm{C}$ atmospheric pressure and $8 \mathrm{M} / \mathrm{L}$ nitric acid solution.

The main scope of the paper is to prove the higher accuracy obtained by using the AI (Artificial Intelligence) [15-17] methods in modelling the operation of the separation cascade, in comparison with the accuracy obtained by using classic methods. The problem of modeling and controlling the separation processes is presented in several papers of the technical literature for different types of isotopes: [20-24]. The ${ }^{18} \mathrm{O}$ isotope is treated in many scientific articles by presenting its direct applications [9,25-27]. In previous papers [28-32], some solutions for modeling and controlling the separation process for the ${ }^{18} \mathrm{O}$ isotope production are presented. By analyzing these solutions, in most of the cases, some simplified linearized models with lumped parameters are proposed for the processes associated to the separation columns, which operate independently (they are not included in the separation cascades). Consequently, the proposed control strategies are designed based on the simplified models. Based on a proposed structure of a nonlinear distributed parameter model [33-37] for the separation cascade operation (model which can be used for different predictions of the ${ }^{18} \mathrm{O}$ isotope concentration dynamics), the aim of this paper is to compare the efficiency of using AI methods versus classical methods to modelling some important nonlinear components of the mentioned model. Another advantage of obtaining an accurate model of the separation cascade is the possibility to include it in an original future ${ }^{18} \mathrm{O}$ isotope control strategy which will generate much better control performances than the actual solutions.

A possible future application for the proposed model is the analysis of the separation cascade energy consumption [38-41]. Based on this analysis solutions for the energy consumption optimization will be proposed.

As a synthesis, the AI-based proposed modeling method is used due to some important aspects which will be following presented.

One of the main aims of the article is to propose a highly accurate mathematical model for the separation cascade, a model that will be used further in different applications, as: a reference model in structures for automatic control of ${ }^{18} \mathrm{O}$ isotope concentration; a reference model in determining the influence of the parametric disturbance that occurs in the cascade operation; a reference model in the energy consumption optimization strategy, etc. Another important aim of the present research is to propose a mathematical model that describes the complete dynamics of the separation cascade. Consequently, the two separation columns from the cascade structure are modelled as distributed parameter processes, their dynamics depending both on time and on the position in relation to their heights. Moreover, in order to have the possibility to simulate and to use properly the proposed model in future applications, the modelling has to be applied considering the entire domains of variation of the signals that occur in the separation plant operation (the modelling of the considered separation process near a steady-state working point is not enough due to the fact that a simplified model will imply the consistent decrease in the performances of the ${ }^{18} \mathrm{O}$ isotope's automatic control system in which it is used as a reference model; in some cases, a simplified model cannot be used for designing a control system). In this context, all the structure parameters of the proposed model are non-stationary ones; more exactly, they present consistent variations in relation to the separation cascade operation regime and intensity. Hence, the separation cascade time constants, "length" constants, separations, 
and other structure parameters are variable and depend on the columns feeding intensity. This aspect implies a strong non-linear behavior of the separation cascade.

In [42-44], mathematical models are proposed for separation processes, but having constant parameters. In this case, the usage of $\mathrm{AI}$ is not necessarily due to the absence of the necessity to learn variable parameters. In $[45,46]$, the authors propose distributed parameter processes for separation processes, based on the Cohen equation [47]. The usage of these type of models has the disadvantage that they cannot be used for highlighting the effects of the parametric disturbances that occur in the separation plant operation. In [48-51], the proposed models are designed for a simplified process, near a steady-state working point. These types of models are not complex enough (they do not cover the entire range of the variation domains of the input and output signals that occur in the separation plant operation) for obtaining high-control performances in the case when they are included in automatic control systems. In references [36,52], a modelling-simulation method for distributed parameter processes is presented (the Matrix of Partial Derivatives of the State Vector method, associated with Taylor series), considering as case study separation processes. This method generates high accuracy but implies consistent processing resources. This aspect represents a significant problem in including this type of model in automatic control structures. In references [53,54], neural networks are used to learn some of the structure parameters of separation processes, but only linear parameters. By comparison, the usage of neural networks in the case of the mathematical model proposed in the paper is more justified since they are used to learn nonlinear functions. In [55], some examples of using neural networks for the direct learning of the separation processes behavior are given. In the case of the approached ${ }^{18} \mathrm{O}$ separation process, due to its complexity, the learning of its behavior using only one neural network, even a high complexity one, is almost impossible (it is possible only by interconnecting more neural networks). Moreover, in [55], the premises of using "hybrid semi-parametric modeling" are introduced. Practically, the proposed model is a hybrid one due to the combining of the analytical modelling with the experimental identification of some of the structure parameters of the separation process and with AI methods.

Consequently, the AI-based proposed modeling covers the following gaps: it generates high accuracy in comparison with other methods, an aspect which generates better performances in further usage of the model in different practical applications; it generates the possibility to adapt the proposed model when the parametric disturbances occur in the operation of the separation plant; it allows the complete modelling of the process (as a distributed parameter process with variable coefficients); and it generates the possibility to avoid simplified models.

\section{The ${ }^{18} \mathrm{O}$ Isotope Production and the Experimental Results}

\subsection{The Separation Cascade Used for ${ }^{18} \mathrm{O}$ Production}

The ${ }^{18} \mathrm{O}$ isotope separation cascade, which is used to obtain the experimental data, is presented in Figure 1 [25]. By using this separation cascade, the ${ }^{18} \mathrm{O}$ isotope separation is made through isotopic exchange in the system $\mathrm{NO}, \mathrm{NO}_{2}-\mathrm{H}_{2} \mathrm{O}, \mathrm{HNO}_{3}$. The separation cascade is composed of two separation columns: PSC - Primary Separation Column and FSC-Final Separation Column. The dimensions of the columns are their height $(h=10 \mathrm{~m})$, the PSC diameter $d_{1}=5 \mathrm{~cm}$ and the FSC diameter $d_{2}=1.4 \mathrm{~cm}$ ). Moreover, Figure 1 highlights the sections of the two columns, which are equal. In order to model the ${ }^{18} \mathrm{O}$ isotope concentration variation in relation to the two columns height, the pumps $\mathrm{P} 1$ and $\mathrm{P} 2$ are used for the supply of the two columns with nitric oxides $\left(\mathrm{NO}, \mathrm{NO}_{2}\right.$ ) (the FSC is supplied at its base with the nitric oxides, having an enriched ${ }^{18} \mathrm{O}$ isotope concentration, obtained at the top of the PSC). Furthermore, the waste (the nitric acid solution $\left(\mathrm{HNO}_{3}\right)$ ), is evacuated from the PSC base using the pipe 2. The phenomenon of ${ }^{18} \mathrm{O}$ isotope enrichment occurs due to circulation in countercurrent of the nitric oxides and of the nitric acid inside of the two columns. The product can be extracted from the top of FSC (using the pipe figured with dashed line) under the form of nitric acid having an increased concentration 
of the ${ }^{18} \mathrm{O}$ isotope. Using the $\mathrm{r}$ independent variable associated with the $0 \mathrm{r}$ axes, the ${ }^{18} \mathrm{O}$ isotope concentration in relation to the two separation columns heights can be highlighted.

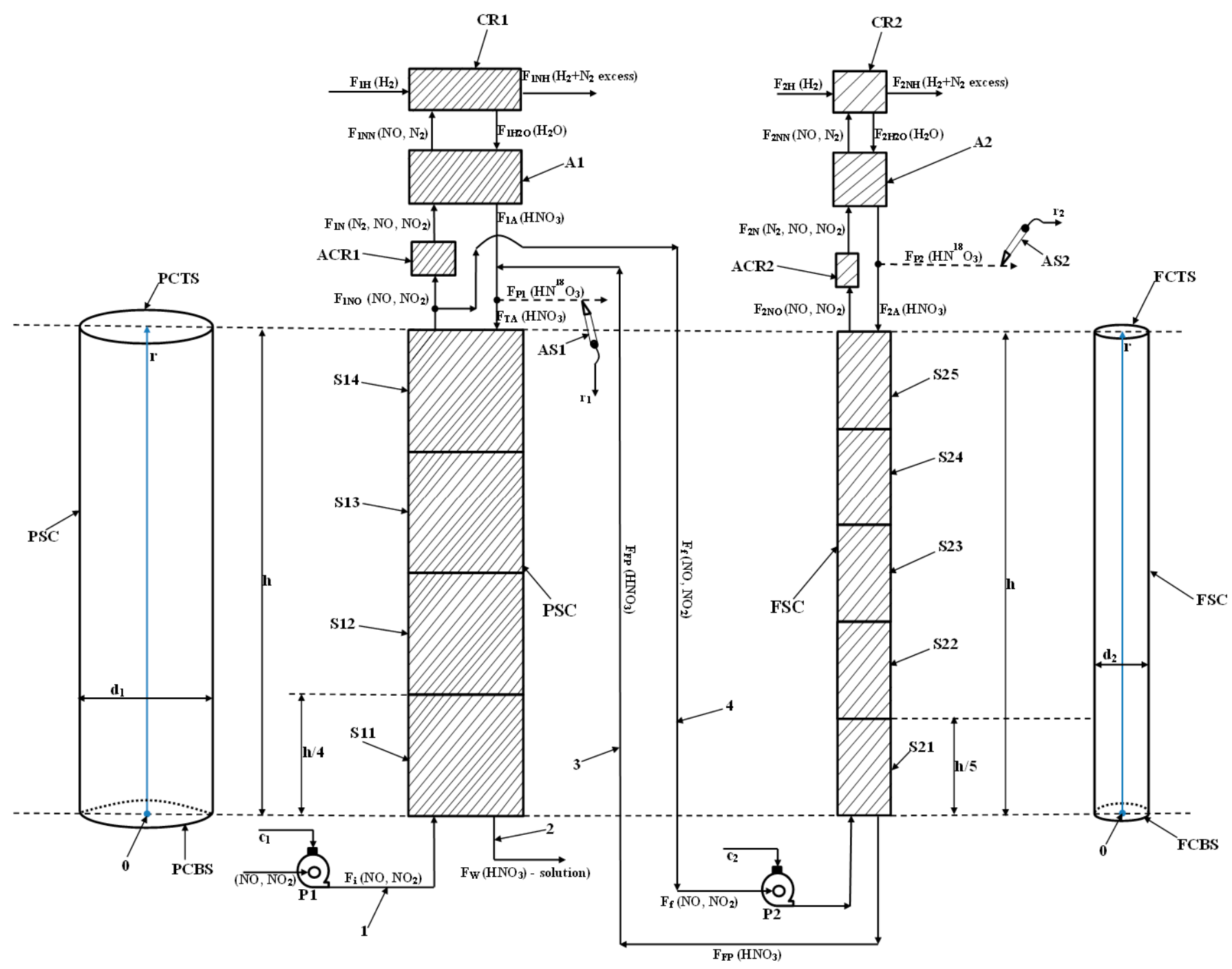

Figure 1. The ${ }^{18} \mathrm{O}$ isotope separation cascade.

Additionally, in Figure 1, the equipment associated to the refluxing systems of the two separation columns is presented: the arc-cracking reactors ACR1 and ACR2, the absorbers $\mathrm{A} 1$ and $\mathrm{A} 2$, respectively, and the catalytic reactors CR1 and CR2.

\subsection{Experimental Results}

The experimental data obtained during the operation of the separation cascade in total reflux regime [5,6] (regime in which the product is not extracted from the plant), are centralized in Tables 1 and 2. The main difficulty in developing the experiments is represented by the fact that the processes from the separation cascade structure are extremely slow processes having time constants with the magnitude order of hundreds of hours. As it results from Table 2, the experiment that generated the presented experimental data went on for 1 month (but some experiments can run up to 8 months). 
Table 1. The parameters used for the separation cascade experimentation.

\begin{tabular}{|c|c|c|}
\hline Separation Column & Parameter & Parameter Value \\
\hline PSC & $\begin{array}{c}\text { Input nitric oxides flow }\left(F_{i}\right) \\
\text { Column temperature }\left(\theta_{1}\right) \\
\text { Concentration of nitric acid }\left(\mathrm{HNO}_{3}\right) \text { solution at the column top } \\
\text { Experiment duration }\end{array}$ & $\begin{array}{l}880 \mathrm{~L} / \mathrm{h} \\
25^{\circ} \mathrm{C} \\
6.6 \mathrm{~mol} / \mathrm{L} \\
750 \mathrm{~h}\end{array}$ \\
\hline FSC & $\begin{array}{l}{ }^{18} \mathrm{O} \text { Isotope concentration obtained at the end of experiment } \\
\text { Input nitric oxides flow }\left(F_{f}\right) \\
\text { Column temperature }\left(\theta_{2}\right) \\
\text { Concentration of nitric acid }\left(\mathrm{HNO}_{3}\right) \text { solution at the column top } \\
\text { Experiment duration } \\
{ }^{18} \mathrm{O} \text { Isotope concentration obtained at the end of experiment }\end{array}$ & $\begin{array}{l}0.7882 \% \\
80 \mathrm{~L} / \mathrm{h} \\
25^{\circ} \mathrm{C} \\
6.9 \mathrm{~mol} / \mathrm{L} \\
750 \mathrm{~h} \\
2.8008 \%\end{array}$ \\
\hline
\end{tabular}

Table 2. The Separation Cascade Response, in Relation to Time.

\begin{tabular}{cccccccccccccc}
\hline & Sample & $\mathbf{1}$ & $\mathbf{2}$ & $\mathbf{3}$ & $\mathbf{4}$ & $\mathbf{5}$ & $\mathbf{6}$ & $\mathbf{7}$ & $\mathbf{8}$ & $\mathbf{9}$ & $\mathbf{1 0}$ \\
\hline Time and Response & 0 & 150 & 233.92 & 309.653 & 375.742 & 451.785 & 531.617 & 619.117 & 702.941 & 727.573 \\
\hline Time [h] & 0.204 & 0.4549 & 0.4784 & 0.549 & 0.5804 & 0.6549 & 0.6902 & 0.7255 & 0.7725 & 0.7882 \\
\hline PSC Response [\%] & 0.204 & 0.7208 & 0.936 & 1.2462 & 1.408 & 1.728 & 2.0059 & 2.3294 & 2.608 & 2.8008 \\
\hline FSC Response [\%] & &
\end{tabular}

In addition to the long-term of the experiments, an important problem is referring to the difficulty of maintaining the normal operation regime of all the auxiliary equipment used for the appropriate operation of the separation cascade.

In Table 3, the experimental data resulted through the FSC operation in total reflux regime, independently by the separation cascade, is presented. The data from Table 3 is essential in determining the dynamic behavior of FSC, which is also, essential in modelling the separation cascade dynamic behavior. The experimental data highlighted in Tables 1-3 are used in order to determine the structure parameters of the proposed mathematical model that describes the cascade operation and is usable for the simulation of the separation cascade dynamics in different operation scenarios of interest. The notations used in Tables 1-3 are valid through the entire paper.

Table 3. The results obtained after FSC experimentation.

\begin{tabular}{|c|c|c|c|c|}
\hline $\begin{array}{l}\text { Experiment } \\
\text { Number }\end{array}$ & Parameter & Parameter Value & Resulted Parameter & $\begin{array}{c}\text { Resulted Parameter } \\
\text { Value }\end{array}$ \\
\hline \multirow{4}{*}{1} & Input nitric oxides flow $\left(F_{f}\right)$ & $80 \mathrm{~L} / \mathrm{h}$ & Elementary separation factor $(\alpha)$ & $1.018[-]$ \\
\hline & Column temperature $\left(\theta_{2}\right)$ & $25^{\circ} \mathrm{C}$ & Maximum obtained separation & $3.7[-]$ \\
\hline & $\begin{array}{l}\text { Concentration of nitric acid } \\
\left(\mathrm{HNO}_{3}\right) \text { solution at the FSC top }\end{array}$ & $6.9 \mathrm{~mol} / \mathrm{L}$ & $\begin{array}{l}\text { Minimum obtained Height of } \\
\text { Equivalent Theoretical Plate (HETP) }\end{array}$ & $13.4 \mathrm{~cm}$ \\
\hline & Experiment duration & $800 \mathrm{~h}$ & $\begin{array}{c}{ }^{18} \mathrm{O} \text { Isotope concentration obtained at } \\
\text { the end of experiment }\end{array}$ & $0.772 \%$ \\
\hline \multirow{4}{*}{2} & Input nitric oxides flow $\left(F_{f}\right)$ & $140 \mathrm{~L} / \mathrm{h}$ & Elementary separation factor $(\alpha)$ & $1.018[-]$ \\
\hline & Column temperature $\left(\theta_{2}\right)$ & $25^{\circ} \mathrm{C}$ & Maximum obtained separation & $7.3[-]$ \\
\hline & $\begin{array}{l}\text { Concentration of nitric acid } \\
\left(\mathrm{HNO}_{3}\right) \text { solution at the FSC top }\end{array}$ & $7.85 \mathrm{~mol} / \mathrm{L}$ & $\begin{array}{l}\text { Minimum obtained Height of } \\
\text { Equivalent Theoretical Plate (HETP) }\end{array}$ & $8.6 \mathrm{~cm}$ \\
\hline & Experiment duration & $600 \mathrm{~h}$ & $\begin{array}{l}{ }^{18} \mathrm{O} \text { Isotope concentration obtained at } \\
\text { the end of experiment }\end{array}$ & $1.485 \%$ \\
\hline \multirow{4}{*}{3} & Input nitric oxides flow $\left(F_{f}\right)$ & $185 \mathrm{~L} / \mathrm{h}$ & Elementary separation factor $(\alpha)$ & $1.018[-]$ \\
\hline & Column temperature $\left(\theta_{2}\right)$ & $25^{\circ} \mathrm{C}$ & Maximum obtained separation & $5.4[-]$ \\
\hline & $\begin{array}{l}\text { Concentration of nitric acid } \\
\left(\mathrm{HNO}_{3}\right) \text { solution at the FSC top }\end{array}$ & $7.85 \mathrm{~mol} / \mathrm{L}$ & $\begin{array}{l}\text { Minimum obtained Height of } \\
\text { Equivalent Theoretical Plate (HETP) }\end{array}$ & $10.1 \mathrm{~cm}$ \\
\hline & Experiment duration & $200 \mathrm{~h}$ & $\begin{array}{l}{ }^{18} \mathrm{O} \text { Isotope concentration obtained at } \\
\text { the end of experiment }\end{array}$ & $1.10 \%$ \\
\hline
\end{tabular}


The separation columns were thermostated at $25{ }^{\circ} \mathrm{C}$, having a double wall made of stainless-steel pipe inside which water flows from a thermostat, which ensures the on-off control of the temperature with a contact thermometer having an accuracy of $0.1^{\circ} \mathrm{C}$. The temperature of the fluids that flow in countercurrent must be kept constant along the entire length of the separation columns so as not to produce the variation of the elementary separation factor and of the chemical composition of the liquid, respectively, of the gaseous phase. The increase in the nitric acid concentration increases the rate of the isotopic exchange reaction, but decreases the elementary separation factor separation, so that an optimal concentration of it must be found, concentration which can lead to a maximum isotopic separation and to an equivalent theoretical plate height (HETP) as low as possible. These changes have a major influence on the separation achieved on each column and on the ${ }^{18} \mathrm{O}$ isotope production of the separation cascade $[8,9,11,12]$.

\section{Mathematical Modeling of the Separation Cascade Operation and the Associated Simulation Structure}

The mathematical model which describes the operation of the previously presented separation cascade is given by the following system of equations:

- The Height of the Equivalent Theoretical Plate (HETP) for the FSC:

$$
\left\{\begin{array}{l}
\operatorname{HETP}_{2}\left(F_{f}\right)=\operatorname{HETP}_{2 c}+K_{H 1} \cdot\left(F_{f}-F_{f c}\right), \text { if } F_{f} \leq F_{f c} \\
\operatorname{HETP}_{2}\left(F_{f}\right)=\operatorname{HETP}_{2 c}+K_{H 2} \cdot\left(F_{f}-F_{f c}\right), \text { if } F_{f}>F_{f c}
\end{array}\right.
$$

(the used notations, being: $K_{H 1}=-0.08 \mathrm{~cm} \cdot \mathrm{h} / \mathrm{L}$ and $K_{H 2}=0.0333 \mathrm{~cm} \cdot \mathrm{h} / \mathrm{L}$ are the gradients of the two linear intervals from the structure of the nonlinear $\mathrm{HETP}_{2}$ function; $\operatorname{HETP}_{2 c}=8.6 \mathrm{~cm}$ is the critical value of $\mathrm{HETP}_{2}$ function; $F_{f c}=140 \mathrm{~L} / \mathrm{h}$ is the critical flow in which the transition from a linear interval to the other one is made);

- $\quad$ The Height of the Equivalent Theoretical Plate (HETP) for the PSC:

$$
\left\{\begin{array}{l}
\operatorname{HETP}_{1}\left(F_{i}\right)=\operatorname{HETP}_{1 c}+K_{H 10} \cdot\left(F_{i}-F_{i c}\right), \text { if } F_{i} \leq F_{i c} \\
\operatorname{HETP}_{1}\left(F_{i}\right)=\operatorname{HETP}_{1 c}+K_{H 20} \cdot\left(F_{i}-F_{i c}\right), \text { if } F_{i}>F_{i c}
\end{array}\right.
$$

(the used notations, being: $K_{H 10}=K_{H 1} \cdot A_{1} / A_{2}$ and $K_{H 20}=K_{H 2} \cdot A_{1} / A_{2}$ are the gradients of the two linear intervals from the structure of the nonlinear $\mathrm{HETP}_{1}$ function and $A_{1}$, respectively, $A_{2}$ are the sections areas of the two columns (PSC and FSC); $\operatorname{HETP}_{1 c}=6.7786 \mathrm{~cm}$ is the critical value of $H E T P_{1}$ function; $F_{i c}=1785.71 \mathrm{~L} / \mathrm{h}$ is the critical flow in which the transition from a linear interval to the other one is made);

- The mathematical model of PSC identified near the steady-state operation point used in the experimental procedure:

$$
\left\{\begin{array}{l}
X_{P S 1}(s)=\frac{K_{10}}{T_{10} \cdot s+1} \cdot U(s) \\
x_{P S}(t, r=h)=x_{0}+L^{-1}\left(X_{P S 1}(s)\right)
\end{array}\right.
$$

(the used notations, being: $H_{1}(s)=K_{10} /\left(T_{10} \cdot s+1\right)$-the transfer function which models the PSC operation for the constant input signal $F_{i}=880 \mathrm{~L} / \mathrm{h} ; x_{0}=0.204 \%$-the natural abundance of the ${ }^{18} \mathrm{O}$ isotope; $U(s)$ - the unit step signal; $L^{-1}$-inverse Laplace transform; $K_{10}=0.8358 \%$ - the PSC proportionality constant; $T_{10}=380.8 \mathrm{~h}$-the PSC time constant; $X_{P S 1}(s)$-intermediary signal; $x_{P S}(t, r=h)$ - the ${ }^{18} \mathrm{O}$ isotope concentration at the output (top) of PSC).

- The separation of the PSC:

$$
S_{P}\left(F_{i}\right)=\alpha^{n_{P}\left(F_{i}\right)}
$$

(where $n_{P}\left(F_{i}\right)$ is the number of the theoretical plates of PSC for $F_{\mathrm{i}}$ ). 
- The number of the theoretical plates of PSC:

$$
n_{P}\left(F_{i}\right)=\frac{h}{\operatorname{HETP}_{1}\left(F_{i}\right)}
$$

- The output concentration of PSC, in steady-state regime (for $r=h$ ):

$$
x_{P s t}=x_{0} \cdot S_{P}\left(F_{i}\right)
$$

- The output concentration of FSC (for $r=h$ ), in steady-state regime:

$$
x_{\text {Fst }}=x_{P s t} \cdot S_{F}\left(F_{f}\right)
$$

where $S_{F}\left(F_{f}\right)$ represents the separation generated by the FSC (defined by a similar equation with (5) but being adapted for the FSC case).

Subsequently in the paper, the following notations are used: $S_{P S T}\left(F_{i}\right)=\left(S_{P}\left(F_{i}\right)-1\right)$ and $S_{F S T}\left(F_{f}\right)=\left(S_{F}\left(F_{f}\right)-1\right)$.

- The nonlinear differential equations, which model the two separation columns dynamics in relation to time:

- for PSC:

$$
T_{1}\left(F_{i}\right) \cdot \frac{d\left(x_{P I}(t)\right)}{d t}+x_{P I}(t)=S_{P S T}\left(F_{i}\right) \cdot x_{0}
$$

- for FSC:

$$
T_{2 i n}\left(F_{f}\right) \cdot \frac{d\left(x_{F I}(t)\right)}{d t}+x_{F I}(t)=S_{F S T}\left(F_{f}\right) \cdot x_{P s t}
$$

where $x_{P I}(t)$ and $x_{F I}(t)$ (for $r=h$ ) are the ${ }^{18} \mathrm{O}$ isotope concentrations increases at the two columns tops, in dynamic regime, over the input concentrations $\left(x_{0}\right.$ in the case of PSC and $x_{P}(t)$ (the output concentration of the ${ }^{18} \mathrm{O}$ isotope at the PSC top) in the case of FSC). (9) and (10) are nonlinear differential equations due to the fact that the time constants $T_{1}\left(F_{i}\right)$ (the time constant of PSC) and $T_{2 i n}\left(F_{f}\right)$ (the intrinsic time constant of FSC) depend on $F_{i}$ and $F_{f}$.

- The adjusted form of the FSC time constant:

$$
T_{2}\left(F_{f}\right)=K_{T 1} \cdot T_{2 i n}\left(F_{f}\right)
$$

where $K_{T 1}$ is the proportionality constant between the two functions, more exactly a correction parameter. After applying a specific identification algorithm, the value $K_{T 1}=3.1693$ is determined.

- The mathematical connection between $T_{1}\left(F_{i}\right)$ and $T_{2}\left(F_{f}\right)$ is given by:

$$
T_{1}\left(F_{i}\right)=K_{T 2} \cdot T_{2}\left(F_{f}\right)
$$

where $K_{T 2}$ is the proportionality constant between the time constants of the two separation columns. After identification, the value $K_{T 2}=0.8955$ resulted. $T_{1}\left(F_{i}\right)$ and $\mathrm{T}_{2}\left(F_{f}\right)$ time constants present parabolic decreasing evolutions.

- The separation of each separation column depending on $r$ independent variable written as a natural exponential function:

$$
S(F)=e^{\frac{h}{R(F)}}
$$


- The "length constant" of the considered separation column, which is a function of the nitric oxides input flow $F$ ( $F_{i}$ in the case of PSC and $F_{f}$ in the case of FSC):

$$
R(F)=\frac{h}{\ln (S(F))}
$$

can be singularized for both PSC and FSC.

- $\quad$ The length constant of the PSC in relation to $F_{i}\left(R_{1}\left(F_{i}\right)\right)$ :

$$
\left\{\begin{array}{l}
R_{1}\left(F_{i}\right)=R_{1 c}+K_{R 10} \cdot\left(F_{i}-F_{i c}\right), \text { if } F_{i} \leq F_{i c} \\
R_{1}\left(F_{i}\right)=R_{1 c}+K_{R 20} \cdot\left(F_{i}-F_{i c}\right), \text { if } F_{i}>F_{i c}
\end{array}\right.
$$

- $\quad$ The length constant of the FSC in relation to $F_{f}\left(R_{2}\left(F_{f}\right)\right)$ :

$$
\left\{\begin{array}{l}
R_{2}\left(F_{f}\right)=R_{2 c}+K_{R 1} \cdot\left(F_{f}-F_{f c}\right), \text { if } F_{f} \leq F_{f c} \\
R_{2}\left(F_{f}\right)=R_{2 c}+K_{R 2} \cdot\left(F_{f}-F_{f c}\right), \text { if } F_{f}>F_{f c}
\end{array}\right.
$$

The identified gradients of the ramps associated to the linear intervals of the curves from (15) and (16), are: $K_{R 10}=-0.3516(\mathrm{~cm} \cdot \mathrm{h}) / \mathrm{L}, K_{R 20}=0.1463(\mathrm{~cm} \cdot \mathrm{h}) / \mathrm{L}, K_{R 1}=K_{R 10} \cdot A_{1} / A_{2}$ and $K_{R 2}=K_{R 20} \cdot A_{1} / A_{2}$ (where $A_{1}=\pi \cdot \frac{d_{1}^{2}}{4}=19.635 \mathrm{~cm}^{2}$ is the section of PSC and $A_{2}=\pi \cdot \frac{d_{2}^{2}}{4}=1.5394 \mathrm{~cm}^{2}$ is the section of FSC).

- The final form of the two separation columns output concentrations:

$$
\begin{gathered}
x_{P}(t, r)=x_{P I}(t) \cdot \frac{F_{r 1}(r)-1}{F_{r 1}(r=h)-1}+x_{0} \\
x_{F}(t, r)=x_{P}(t, r=h) \cdot\left(S_{F}\left(t, F_{f}(t)\right)-1\right) \cdot \frac{F_{r 2}(r)-1}{F_{r 2}(r=h)-1}+x_{P}(t, r=h)
\end{gathered}
$$

where $F_{r 1}\left(r, F_{i}\right)=\exp \left(r / R_{1}\left(F_{i}\right)\right)$ for PSC, $F_{r 2}\left(r, F_{f}\right)=\exp \left(r / R_{2}\left(F_{f}\right)\right)$ for FSC, $F_{r P S C}(r)=$ $\left(F_{r 1}(r)-1\right) /\left(F_{r 1}(r=h)-1\right)$ and $F_{r F S C}(r)=\left(F_{r 2}(r)-1\right) /\left(F_{r 2}(r=h)-1\right)$. The $F_{r P S C}(r)$ and $F_{r F S C}(r)$ functions highlight the proportions of the ${ }^{18} \mathrm{O}$ isotope concentration in a certain position of the columns' height, in relation to the ${ }^{18} \mathrm{O}$ isotope concentrations at their top. Practically, the $F_{r P S C}(r)$ and $F_{r F S C}(r)$ functions model the concentration dynamics on the columns' height.

The following functions: $\operatorname{HETP}_{1}\left(F_{i}\right), T_{1}\left(F_{i}\right)$ and $R_{1}\left(F_{i}\right)$, respectively, the $\operatorname{HEPT}_{2}\left(F_{f}\right)$, $T_{2}\left(F_{f}\right)$ and $R_{2}\left(F_{f}\right)$, are nonlinear ones. The simulation of the previously presented separation cascade model can be made only if the instantaneous values of the six mentioned functions (in relation to the input flows $F_{i}$ and $F_{f}$ ) are available.

The input-output datasets are obtained by sampling the signals used for training the two neural networks (the input signal $\left(F_{i}\right)$ and the output signals $\operatorname{HETP}_{1}\left(F_{i}\right), T_{1}\left(F_{i}\right)$ and $R_{1}\left(F_{i}\right)$ in the case of NNPSC; the input signal $\left(F_{f}\right)$ and the output signals $\operatorname{HEPT}_{2}\left(F_{f}\right), T_{2}\left(F_{f}\right)$ and $R_{2}\left(F_{f}\right)$ in the case of NNFSC) considering, for each, the corresponding sample value necessary to divide the entire variation domain in 1250 equidistant intervals. The testing input datasets are obtained by sampling the input signals $\left(F_{i}\right)$ and $\left(F_{f}\right)$ considering, for each, the corresponding sample value necessary to divide the entire variation domain in 2500 equidistant intervals (resulting 2501 samples). The MSE values presented in Table 4 are arrived at using the two neural networks responses to the mentioned testing input datasets and the analytical values of the $\operatorname{HETP}_{1}\left(F_{i}\right), T_{1}\left(F_{i}\right), R_{1}\left(F_{i}\right), \operatorname{HEPT}_{2}\left(F_{f}\right), T_{2}\left(F_{f}\right)$, respectively, the $R_{2}\left(F_{f}\right)$ functions. 
Table 4. The Centralizer with the MSE Values Associated to the Obtained Neural Solutions.

\begin{tabular}{|c|c|c|c|c|c|c|}
\hline Neural Network & & NNPSC & & & NNFSC & \\
\hline Considered Output from NN & $S_{P S T}\left(F_{i}\right)$ & $T_{1}\left(F_{i}\right)$ & $R_{1}\left(F_{i}\right)$ & $S_{F S T}\left(F_{f}\right)$ & $T_{2}\left(F_{f}\right)$ & $R_{2}\left(F_{f}\right)$ \\
\hline $\begin{array}{l}\text { MSE between the NN output } \\
\text { values and the real } \\
\text { function values }\end{array}$ & $7.91 \times 10^{-4}$ & $7.20 \times 10^{-5} \mathrm{~h}$ & $0.81 \times 10^{-2} \mathrm{~cm}$ & $5.73 \times 10^{-4}$ & $6.46 \times 10^{-5} \mathrm{~h}$ & $1.67 \times 10^{-2} \mathrm{~cm}$ \\
\hline
\end{tabular}

The feed-forward neural architecture is used due to its universal approximation property, and because this architecture is complex enough to learn the behavior of the $\operatorname{HETP}_{1}\left(F_{i}\right), T_{1}\left(F_{i}\right), R_{1}\left(F_{i}\right), H E P T_{2}\left(F_{f}\right), T_{2}\left(F_{f}\right)$, respectively, the $R_{2}\left(F_{f}\right)$ functions. The six mentioned functions are not recursive functions, their instantaneous values not being dependent by their past samples. In this context, the usage of a recurrent neural network is not justified.

Regarding the Hyperparameters of the two neural structures, in each case, one hidden layer was defined in order not to increase the computations complexity during their training procedures. The increase in the number of the hidden layers implies the consistent increase in the computation's complexity during their training procedures, but it does not guarantee higher performances (regarding to the generated accuracies). The number of the neurons from the hidden layer was iteratively determined. The two neural networks training was performed iteratively, starting with a number of three neurons in the hidden layer, and increasing, from a training, to the next one, the hidden layer size with one neuron. For each neural network, the algorithm was stopped when, from an iteration to the next one, the obtained errors (MSEs between the approximated output signals and their analytical values) started to increase. The used activation functions for the neurons from the two neural networks hidden layers are the bipolar sigmoid functions (hyperbolic tangent functions) since the mentioned neural networks learn the behavior of nonlinear parameters. Moreover, in both cases, the size of the output layer is three (the number of the output signals), all the output neurons are linear (in order to implement the linear combination of the output signals of the neurons from the hidden layer).

The $\operatorname{HETP}_{1}\left(F_{i}\right), T_{1}\left(F_{i}\right), R_{1}\left(F_{i}\right), H E P T_{2}\left(F_{f}\right), T_{2}\left(F_{f}\right)$, and $R_{2}\left(F_{f}\right)$ functions dynamics can be learned with a more complex MIMO neural network, too. A more complex MIMO neural network would have the $\left(F_{i}\right)$ and $\left(F_{f}\right)$ flows as input signals and all the six mentioned functions as output signals. However, the implementation of two neural networks is preferred instead of a more complex one due to the following aspect: the PSC is fed with flows $\left(F_{i}\right)$ higher with between 8 and 15 times more than the flows $\left(F_{f}\right)$, which with FSC is fed; this difference is consistently higher than that of the value differences between the output functions $\left(\operatorname{HETP}_{1}\left(F_{i}\right)\right.$ and $\operatorname{HEPT2}\left(F_{f}\right), T_{1}\left(F_{i}\right)$ and $T_{2}\left(F_{f}\right)$, respectively, $R_{1}\left(F_{i}\right)$ and $\left.R_{2}\left(F_{f}\right)\right)$; due to this aspect, the training, in the case of a more complex MIMO neural network, is a little less efficient than in the case of training the proposed two neural networks; consequently, using two different neural networks instead of a more complex one, the obtained accuracy is slightly higher, a fact that implies the determining of more accurate mathematical model for the separation process.

In this context, for the precise mathematical dependency between the input flows $F_{i}$ and $F_{f}$, respectively, the functions $\operatorname{HETP}_{1}\left(F_{i}\right), T_{1}\left(F_{i}\right), R_{1}\left(F_{i}\right), H E P T_{2}\left(F_{f}\right), T_{2}\left(F_{f}\right)$ and $R_{2}\left(F_{f}\right)$, two neural networks are used. The general structure of the two neural networks is presented in Figure 2. 


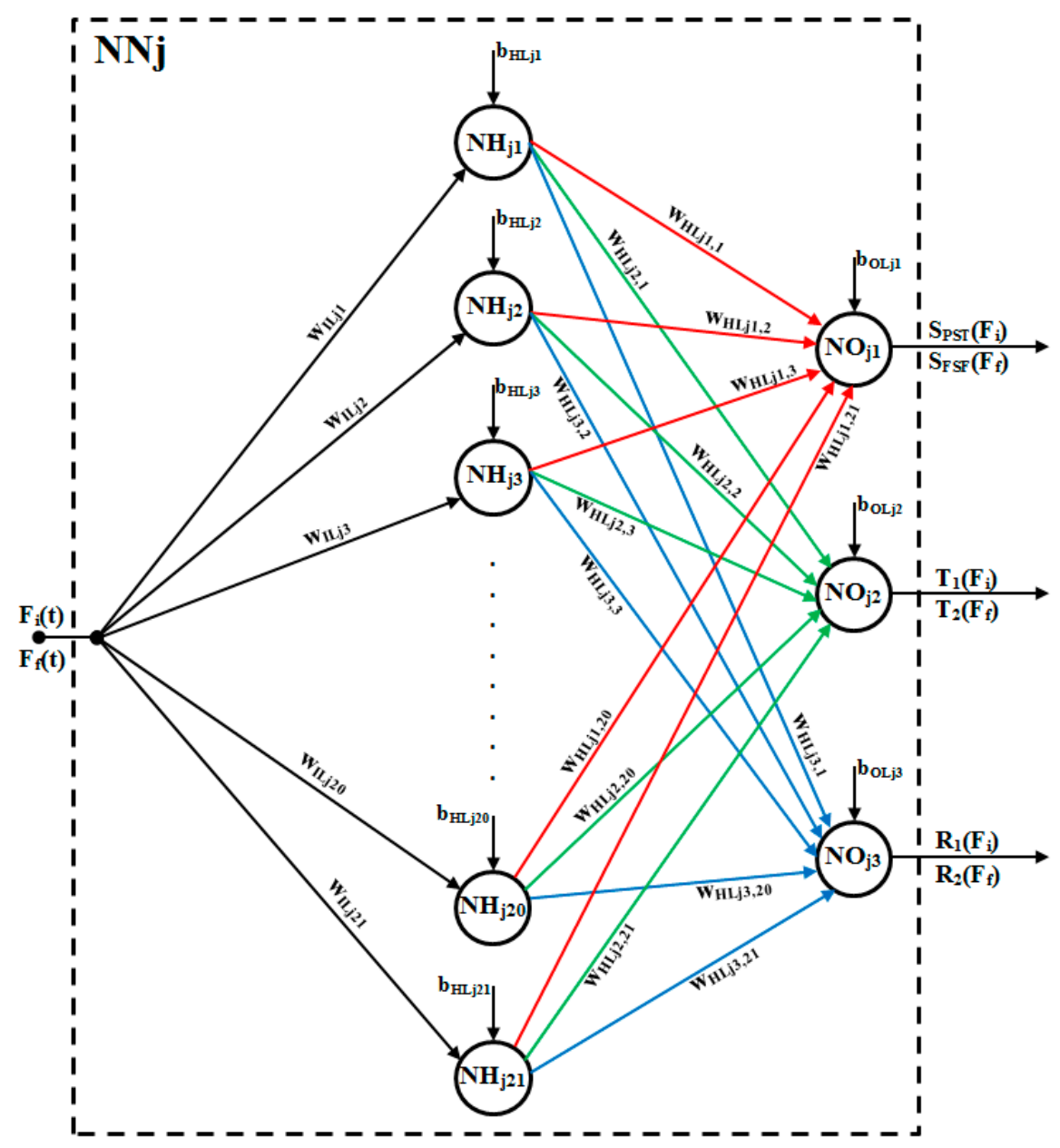

Figure 2. The general structure of the two neural networks.

In Figure 2, " $j "$ is referring to PSC or FSC. For $j=P S C$, only the signals above the arrows are considered and for $j=F S C$, only the signals below the arrows are considered. In both cases, $\mathrm{NNj}$ is as a feed-forward fully connected neural network [56-58], containing in the structure:

- A hidden layer with 21 nonlinear neurons having hyperbolic tangent transfer function.

- The output layer with 3 linear neurons.

The size of the hidden layer resulted after optimizing the learning precision of the two neural networks. The training of the two neural networks is made using, for each function, 1251 pairs of input-output samples.

The training is accomplished by applying the Levenberg-Marquardt algorithm [59-61], the maximum allowed number of epochs being set to 50,000. The target error (MSE) is set at $10^{-10}(\mathrm{mu})((\mathrm{mu})$ being the appropriate measurement unit for each output signal). After the training process, the two obtained neural solutions are tested by computing each MSE value corresponding to each output signal; the obtained values are centralized in Table 4 . The insignificant values of all MSE from Table 5 prove the high accuracy generated by the two proposed neural models.

Table 5. The centralizer with the MSE values associated to the obtained polynomial solutions.

\begin{tabular}{ccccc}
\hline $\begin{array}{c}\text { Degree of the Polynomial } \\
\text { Approximating Function }\end{array}$ & 10th Degree & 20th Degree & 50th Degree & 100th Degree \\
\hline MSE & 0.0744 & 0.0362 & 0.0220 & 0.0275 \\
\hline
\end{tabular}


The details of the proposed neural network's structure and its parameters are presented in Figure 3.

Neural Network Structure: Feed-Forward Fully Connected Neural Network

One Input Layer which contains the input signal: $F_{i}(t)$ if $j=P S C$, or $F_{f}(t)$ if $j=F S C$

One Hidden Layer which contains: $n=21$ neurons $\left(\mathbf{N H}_{\mathbf{j k}}\right)$ where $\mathrm{k} \in\{1,2, \ldots \ldots, \mathrm{n}\}, \mathbf{j} \in\{$ PSC, FSC $\}$

One Output Layer which contains: $m=3$ neurons $\left(\mathrm{NO}_{j 1}\right)$ where $l \in\{1,2,3\}, \mathrm{j} \in\{\mathrm{PSC}, \mathrm{FSC}\}$

The Kernel (Activation) Functions: Bipolar Sigmoid Function (Hyperbolic Tangent Function)

for $\mathrm{NH}_{\mathrm{jk}}$ neurons and Linear Function for $\mathrm{NO}_{\mathrm{jl}}$ neurons

The Vectors and the Matrix which contain the neural network weights and bias values:

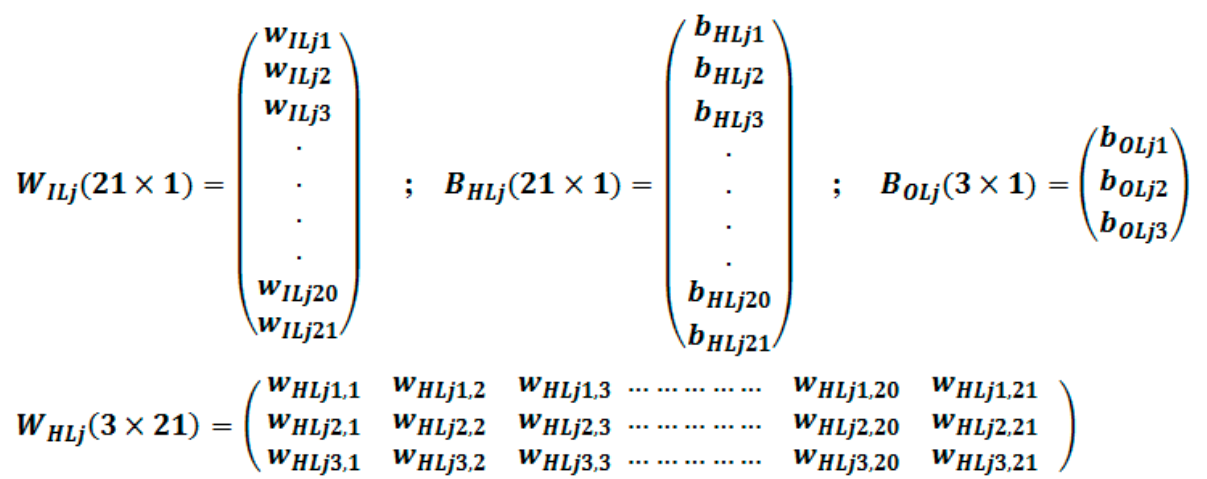

Figure 3. The details of the proposed neural network's structure and its parameters.

Considering the previously presented Equations (2)-(18), the proposed mathematical model of the separation cascade can be implemented through the functional scheme presented in Figure 4. In order to be simulated, the diagram from Figure 4 is implemented in MATLAB/Simulink. As it is presented in Figure 4, the upper part of the scheme implements the mathematical model of PSC, and the lower part of the scheme implements the mathematical model of FSC. By connecting the two models as it is presented in Figure 4, the separation cascade model, results. In Figure 4, all the signals which connect the elements are highlighted over the corresponding arrows.

The $\int() d t$ notation signifies the computation of the integral in relation to the time of the input signal in the corresponding element. Moreover, the elements $f\left(r, R_{1}\right)$ and $f\left(r, R_{2}\right)$ are used to compute the $F_{r P S C}(r)$ and $F_{r F S C}(r)$ functions.

The two neural networks previously trained, generate the following output signals:

$$
\begin{gathered}
Y_{P S C}=W_{H L j} \cdot\left[\tan \operatorname{sig}\left(W_{I L j} \cdot F_{i}(t)+B_{H L j}\right)\right]+B_{O L j} \\
Y_{F S C}=W_{H L j} \cdot\left[\tan \operatorname{sig}\left(W_{I L j} \cdot F_{f}(t)+B_{H L j}\right)\right]+B_{O L j}
\end{gathered}
$$

The output column vector from NNPSC is $Y_{P S C}=\left[\begin{array}{lll}S_{P S C}\left(F_{i}(t)\right) & T_{1}\left(F_{i}(t)\right) & R_{1}\left(F_{i}(t)\right)\end{array}\right]^{\tau}$, and the output column vector from NNFSC is $Y_{F S C}=\left[\begin{array}{lll}S_{F S C}\left(F_{f}(t)\right) & T_{2}\left(F_{f}(t)\right) & R_{2}\left(F_{f}(t)\right)\end{array}\right]^{\tau}$ (in both cases, the notation " $\tau$ " signifies the transpose operator application).

The functional scheme from Figure 4 can be used to simulate the separation cascade behavior for any value of $F_{i}(t)$ and $F_{f}(t)$ input signals, both in open loop and in closed loop regime. Moreover, by using this scheme, the separation cascade dynamics, both in relation to $(t)$ and $(r)$ independent variables, can be highlighted.

The simulations of the separation cascade operation are made using the structure presented in Figure 4 implemented in MATLAB/Simulink [62]. The simulations are focused on highlighting the most important functional properties of the separation cascade. 


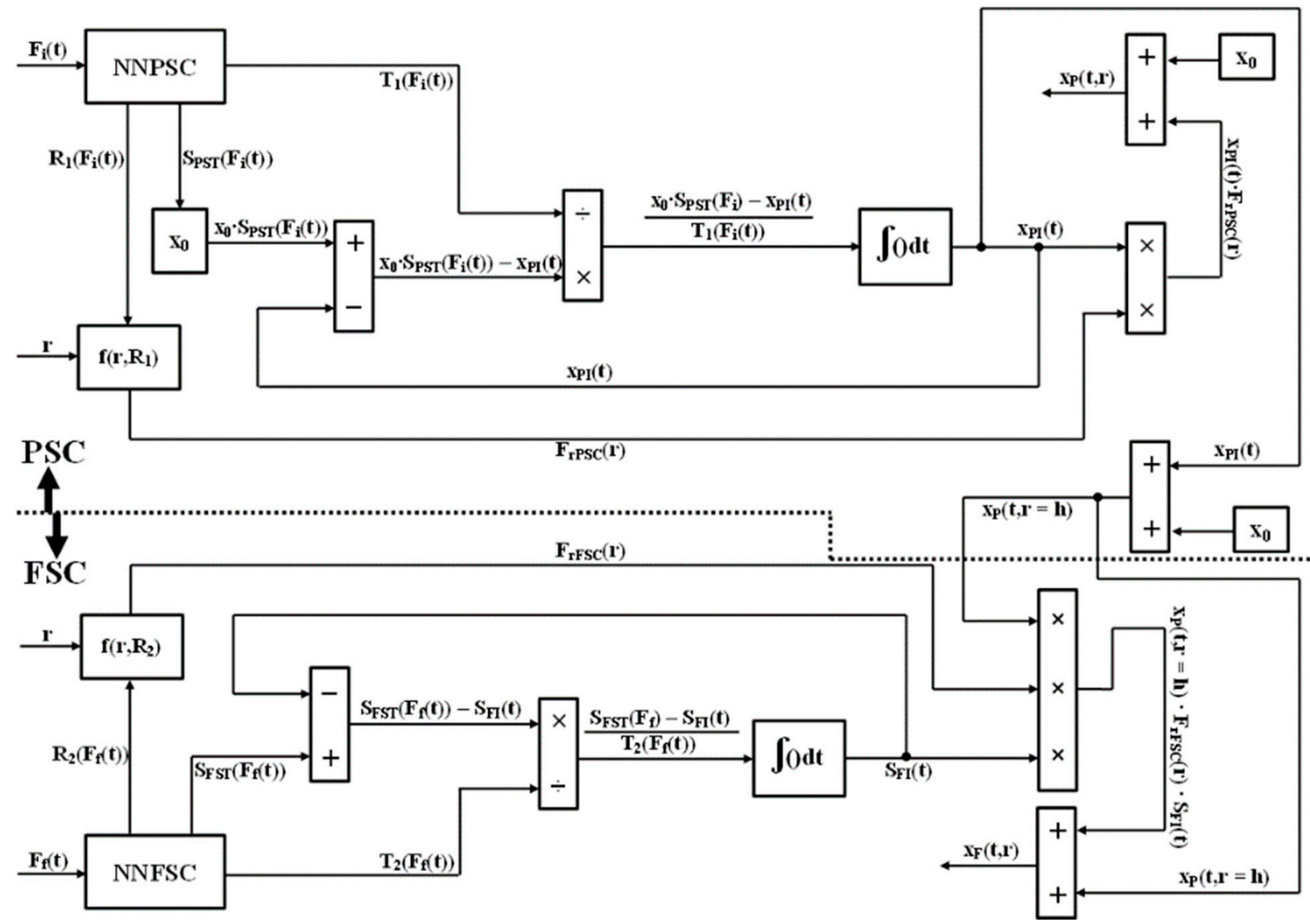

Figure 4. The implementation proposed for the mathematical model of the separation cascade.

\section{Proof through Simulation of the Neural Network's Usage Necessity}

The implementation of the neural networks for modeling the separation cascade dynamics is justified due to the following three aspects:

1. The consistently higher accuracy generated by the neural models [63-65] comparing to the models obtained using other modeling procedures, for the same number of parameters;

2. The possibility to implement an online adaption algorithm for some of the neural network's parameters, in order to adapt the proposed model at the physical variations of the separation cascade structure parameters;

3. The possibility to use neural networks for the future intelligent control of the separation cascade and to apply the same training algorithm as in the case of the proposed model.

\subsection{Proof of Neural Model Higher Accuracy}

In order to highlight the mentioned advantages, two other types of models (the polynomial models and the Spline type models) are comparatively studied with the proposed neural model.

(1) The polynomial approximating functions.

The polynomial approximating function's general form is given by:

$$
P(z)=\sum_{i=0}^{n} p_{i} \cdot z^{i}=p_{n} \cdot z^{n}+p_{n-1} \cdot z^{n-1}+\ldots+p_{1} \cdot z+p_{0}
$$

where $n$ is its degree and $p_{i}(i \in\{0,1,2,3, \ldots, n\})$ are its coefficients. Moreover, the polynomial approximating function variable is denoted by $z$. The approximation of a certain function using the polynomial function consists of determining (identifying) the 
values of the $p_{i}(i \in\{0,1,2,3, \ldots, n\})$ coefficients in order to obtain the best fit between the two functions. The limitations of the polynomial approximation can be easily highlighted in the cases of the $S_{F S T}\left(F_{f}\right)$ and the $S_{P S T}\left(F_{i}\right)$ functions. By varying the polynomial degree, it its observed that the fitting quality of the results is varying too. Consequently, a study regarding the polynomial degree influence over the approximation accuracy is carried on. In the case of the $S_{F S T}\left(F_{f}\right)$ function, 1251 samples were considered in order to be processed with the purpose of obtaining the polynomial approximating functions. By using these samples and applying the Least Square Method [66], three polynomial approximating functions are determined, having the degrees: $n_{1}=10, n_{2}=20$ and $n_{3}=50$. The comparative graph between the real form of the $S_{F S T}\left(F_{f}\right)$ function and the responses of the three obtained polynomial approximating functions is presented in Figure 5.

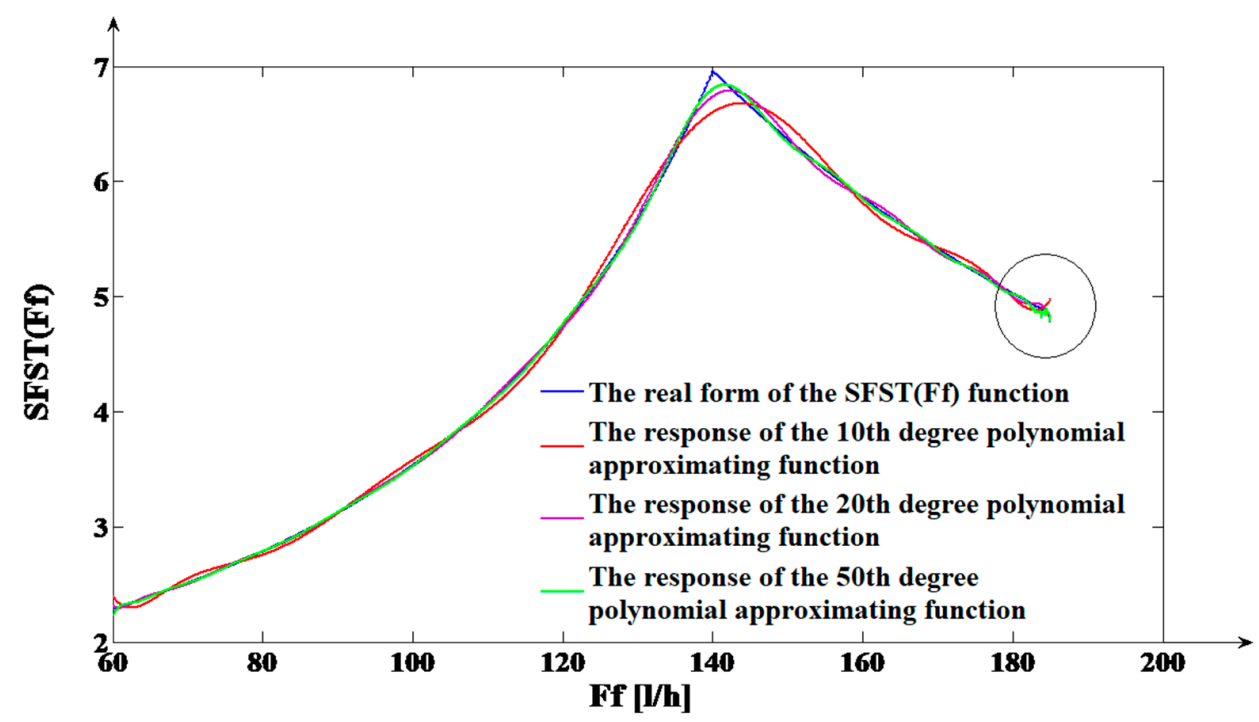

Figure 5. The comparative graph between the $S_{F S T}\left(F_{f}\right)$ function and the responses of the three determined polynomial approximating functions.

From Figure 5, a low accuracy of the polynomial approximating functions in modeling the $S_{F S T}\left(F_{f}\right)$ function, results.

This conclusion is obvious since between the three polynomial responses and the $S_{F S T}\left(F_{f}\right)$ function, a consistent difference in values on certain domains of $F_{\mathrm{f}}$ signal values can be observed (the most consistent variations occur in the neighborhood of the $F_{f_{c}}$ value). Another important aspect is referring to the fact that if we increase the degree of the polynomial approximating function, in the domain of $\mathrm{F}_{\mathrm{f}}$ high values (in the neighborhood of $F_{\text {fmax }}$; this domain is highlighted on the right part of Figure 5 with a circle), the corresponding response presents oscillations. The higher the polynomial approximating function degree, the higher its response oscillations. Consequently, a lower fit between the polynomial function response and the $S_{F S T}\left(F_{f}\right)$ function will be obtained for high values of $F_{f}$ and implicitly (as error) for the entire range of $F_{f}$ values. The low quality of the polynomial identification can be also highlighted through the MSE values obtained between the responses of the three polynomials presented in Figure 5 and the response of $S_{F S T}\left(F_{f}\right)$ function, values centralized in Table 5.

All the MSE values from Table 5 are computed on 1251 pairs of samples of $S_{F S T}\left(F_{f}\right)$ function response and of each polynomial response. In the last column of Table 5, the MSE value associated to a 100th degree polynomial approximating function (for the $S_{F S T}\left(F_{f}\right)$ function) is presented. From Table 5, the result is that increasing the degree of the polynomial approximating function until the value of 50, the approximation accuracy increases, but after this value, the approximation accuracy starts to decrease. The explanation of this phenomenon is given by the following: the oscillations occurrence in the domain of $F_{f}$ signal high values, for the polynomials with higher degrees; the oscillations' amplitude 
increases at the polynomial degree increase. In this context, it can be remarked that the MSE value is higher in the case of using the 100th degree polynomial than in the case of the 50th degree polynomial. Consequently, the final solution for the $S_{F S T}\left(F_{f}\right)$ function approximation using polynomial functions is obtained using a 50th degree polynomial.

However, by comparing the neural approximation accuracy with the 50th degree polynomial approximation accuracy, the neural model can be observed to be much more accurate.

The better performances generated by the proposed neural model are proven by the MSE values: the value of MSE computed in the case of the neural model, presented in Table $4\left(M S E=5.73 \cdot 10^{-4}\right)$ is much lower (of more than 100 times) than the lowest value presented in Table $5\left(M S E=2 \cdot 2 \cdot 10^{-2}\right.$; generated by the 50 th degree polynomial approximating function).

In the case of the $S_{P S T}\left(F_{i}\right)$ function, the polynomial approximating functions are determined, too. After applying the same procedure as in the case of $S_{F S T}\left(F_{f}\right)$ function and considering the same degrees for the polynomials $\left(n_{1}=10, n_{2}=20\right.$ and $\left.n_{3}=50\right)$, the same conclusions as in the case of $S_{F S T}\left(F_{f}\right)$ function, results.

The MSE values between the responses of the three polynomials and the real response of $S_{P S T}\left(F_{i}\right)$ function are computed on 1251 pairs of samples of $S_{P S T}\left(F_{f}\right)$ function response and of each polynomial response. These values are centralized in Table 6.

Table 6. The centralizer with the MSE values associated to the obtained polynomial approximating functions (case of approximating the $S_{P S T}\left(F_{i}\right)$ function).

\begin{tabular}{ccccc}
\hline Degree of the Polynomial Approximating Function & 10th Degree & 20th Degree & 50th Degree \\
\hline MSE & 0.2059 & 0.1009 & 0.0605 \\
\hline
\end{tabular}

Consequently, the same conclusion that the proposed neural model is much more accurate, results. This conclusion is confirmed, also, by the consistent difference between the MSE values (in the case of the neural model, the value MSE $=7 \cdot 91 \cdot 10^{-4}$ is obtained (Table 5), which is lower (almost of 100 times) than the lowest value from Table 6 (MSE = 0.0605 obtained for the 50th degree polynomial).

In order to compare the effects of the two types of the approximations (neural and polynomial) accuracies, the comparative graph from Figure 6 is presented. In Figure 6, the most probable response of the separation cascade is comparatively presented with the separation cascade models responses obtained by using the neural and the polynomial approximation types (for the same simulation, both the $S_{P S T}\left(F_{i}\right)$ and the $S_{F S T}\left(F_{f}\right)$ functions are approximated using the same approximation type).

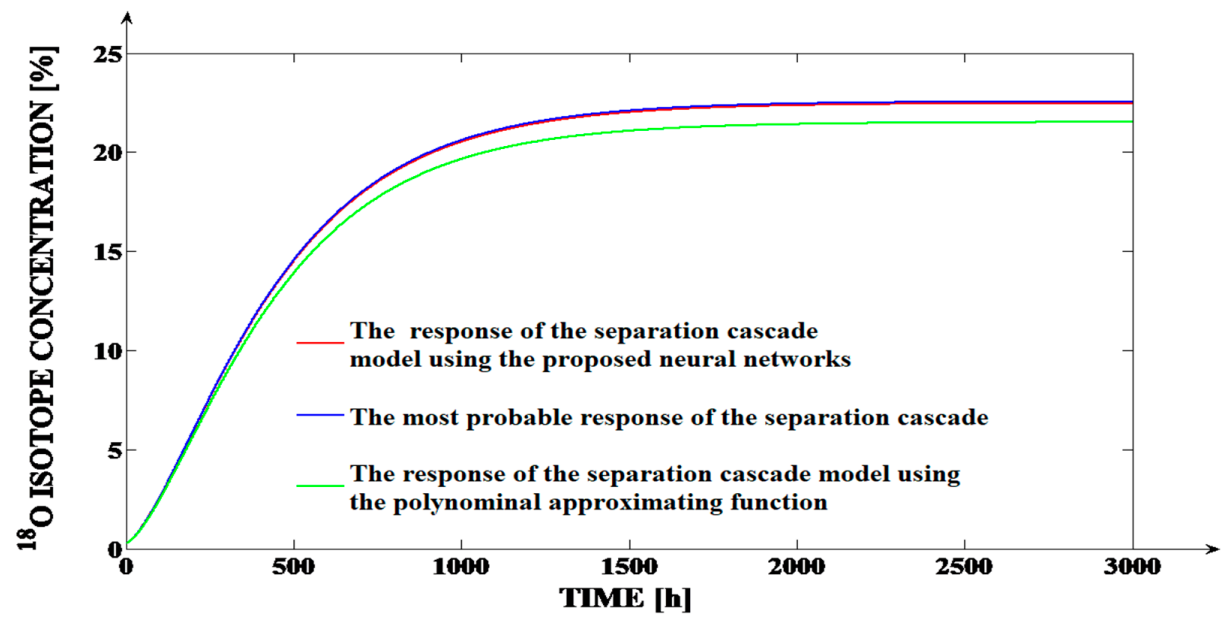

Figure 6. The effects of the $S_{P S T}\left(F_{i}\right)$ and of the $S_{F S T}\left(F_{f}\right)$ functions approximation, using neural networks, respectively, polynomial functions. 
The simulations from Figure 6 are performed for the input flows $F_{i}=F_{i c}=1785.71 \mathrm{~L} / \mathrm{h}$ (in the PSC) and $F_{f}=F_{f_{c}}=140 \mathrm{~L} / \mathrm{h}$ (in the FSC), for which the errors between the theoretical forms of the $S_{P S T}\left(F_{i}\right)$, respectively, the $S_{F S T}\left(F_{f}\right)$ functions and the responses of the two types of their approximations (neural and polynomial) are maximum. For the three cases, the values of the $S_{P S T}\left(F_{i c}\right)$ and the $S_{F S T}\left(F_{f c}\right)$ functions are centralized in Table 7 . For both functions, the values deviations of the neural approximations in relations to the theoretical values $\left(\Delta S_{P S T}\left(F_{i c}\right)=0.0265\right.$ and $\left.\Delta S_{F S T}\left(F_{f c}\right)=0.0166\right)$ are much smaller than the values deviations of the polynomial approximations in relations to the theoretical values $\left(\Delta S_{P S T}\left(F_{i c}\right)=0.4332\right.$ and $\left.\Delta S_{F S T}\left(F_{f c}\right)=0.125\right)$.

Table 7. The values of $S_{P S T}\left(F_{i c}\right)$ and $S_{F S T}\left(F_{f c}\right)$ functions.

\begin{tabular}{ccccccc}
\hline Considered Function & & $S_{P S T}\left(F_{i c}\right)$ & & & $S_{F S T}\left(F_{f c}\right)$ & Noural \\
\hline Model Type & Theoretical & Neural & Polynomial & Theoretical & Nolynomial \\
\hline Function Value & 12.8988 & 12.8723 & 12.4656 & 6.96 & 6.9434 & 6.835 \\
\hline
\end{tabular}

This aspect implies a much better accuracy generated by the neural model in comparison to the polynomial model. Analyzing Figure 6, a much better superposition of the response generated by the separation process model (over the most probable response) can be remarked in the case when the $S_{P S T}\left(F_{i}\right)$ and the $S_{F S T}\left(F_{f}\right)$ functions are approximated using neural networks than in the case when they are approximated using polynomial functions. The better accuracy obtained by using the neural approximations is proven through the MSE values computed (on 3001 pairs of samples considering the sampling time $\Delta T_{S}=1 \mathrm{~h}$ ) between the responses from Figure 6. Consequently, using the values of the red and of the blue curves from Figure 6, the error MSE $=0.0793 \%$ is computed. This error is much smaller than the $M S E=0.9215 \%$ error computed between the values of the green and of the blue curves from Figure 6.

In conclusion, by using the neural approximation of the $S_{P S T}\left(F_{i}\right)$ and the $S_{F S T}\left(F_{f}\right)$ functions, we obtain an accurate model of the separation cascade operation, but in the case of the polynomial approximation, we obtain an unacceptable accuracy (an MSE value equal to $0.9215 \%$, and a deviation of the cascade response in steady-state regime of $1 \%$ are considered "huge" deviations for the isotope separation applications).

An interesting comparison between different types of approximations can be made referring to their number of coefficients. In the case of the 50th degree polynomial approximation, 51 coefficients are used, according to $(21)\left(p_{i}(i \in\{0,1,2,3, \ldots, 50\})\right)$. In the case of the neural approximation, a total of 108 weights and bias values are used, but they are approximating 3 functions in the same time (for example, considering NNPSC, it approximates the $S_{P S T}\left(F_{i}\right), T_{1}\left(F_{i}\right)$ and $R_{1}\left(F_{i}\right)$ functions).

Hence, the result is that for each function, an average of 36 (the third part from 108) parameters are used.

For each obtained neural solution (having 21 nonlinear neurons in the hidden layer and 3 linear neurons in the output layer), the total of 108 can be split in: 21 input weights $+63(3 \cdot 21)$ weights between the hidden and the output layer +21 bias values of the neurons from the hidden layer +3 bias values for the neurons of the output layer. Taking in account all the conclusions above, using the neural approximation, we obtain a better accuracy than in the case of using the polynomial approximation and, at the same time, with less model parameters $(36<51)$.

Another type of approximation that was considered is the interpolation Spline function. In contrast to the polynomial approximation functions, in the case of the interpolation Splines, the variation domain of the input variable (signal) is decomposed in a certain number of subdomains, each subdomain being bounded by two consecutive interpolation points. If we preserve the general notation of the variable from (21), then an example of a subdomain is $\left[z_{i}, z_{i+1}\right]$, where $z_{i}$ and $z_{i+1}$ are two consecutive interpolation points and $i \in\{1,2,3, \ldots \ldots, n-1\}$, where $n$ represents the total number of the considered 
interpolation points (the $n$ value is restricted by the number of the available interpolation points or, if there are available a consistent number of interpolation points, the $n$ value can be imposed in order to limit the total number of the interpolation Spline parameters). For the considered technical application, the case of the Cubic interpolation Spline function is considered. Consequently, the variation form of the approximated function, on each resulted subdomain $\left[z_{i}, z_{i+1}\right]$, is estimated using the Cubic interpolation Spline from (22):

$$
S_{i}(z)=a_{i} \cdot\left(z-z_{i}\right)^{3}+b_{i} \cdot\left(z-z_{i}\right)^{2}+c_{i} \cdot\left(z-z_{i}\right)+d_{i}
$$

where $i \in\{1,2,3, \ldots \ldots, n-1\}$. For each subdomain (subinterval) the $a_{i}, b_{i}, c_{i}$ and $d_{i}$ can be determined using the natural cubic spline method [53]. The notation $f_{i}=f\left(z_{i}\right)$ is used for the approximated function value for the input variable values $z_{i}(i \in\{1,2,3, \ldots \ldots, n-1\})$, values which are known.

Then, the approximation of the $S_{P S T}\left(F_{i}\right)$ and the $S_{F S T}\left(F_{f}\right)$ functions, using the Cubic interpolation Spline is presented. In order to obtain a similar number of parameters of the interpolation Spline function (cumulated on all subintervals) with the parameters of the proposed neural approximation, a number of 26 interpolation points are considered. Consequently, 25 subintervals of the $F_{i}$ and $F_{f}$ input signals result. As a remark, the considered interpolation points are considered equidistant. It results that the total number of parameters of each from the two interpolation Spline functions, which are used for the approximation of the $S_{P S T}\left(F_{i}\right)$ and the $S_{F S T}\left(F_{f}\right)$ functions, is 100 (4 parameters $a_{i}, b_{i}, c_{i}$ and $d_{i}$ for each of the 25 subintervals).

In the case of the $F_{f}$ input signal, 26 interpolation points are considered, starting with the lowest possible value of $60 \mathrm{~L} / \mathrm{h}$ and maintaining the step $\Delta F_{f}=5 \mathrm{~L} / \mathrm{h}$ (hence, including the highest possible value of $185 \mathrm{~L} / \mathrm{h}$ ). After applying the natural cubic spline method and finding for all 25 intervals the $a_{i}, b_{i}, c_{i}$, and $d_{i}$ coefficients, the comparative graph from Figure 7 can be presented.

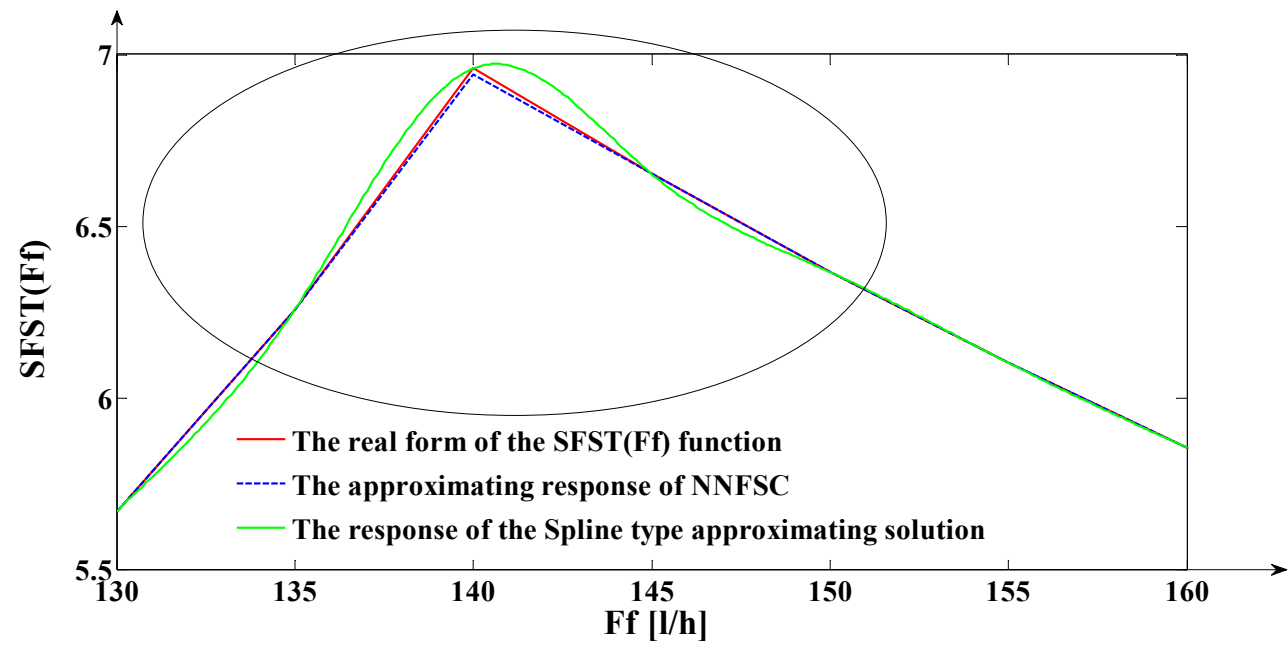

Figure 7. The comparative graph between the $S_{F S T}\left(F_{f}\right)$ function and the responses of the determined Cubic interpolation Spline, respectively, of the proposed neural approximation.

From Figure 7, we notice that the response generated by the Spline type approximating solution presents visible deviations in relation to the other two responses, aspect which implies its lower accuracy. The same conclusion is obtained as a result of the $S_{P S T}\left(F_{i}\right)$ function variation. In Figure 7, the interval of the responses in which the most consistent deviation between the response of the Spline type approximation and the real form of $S_{F S T}\left(F_{f}\right)$ function, is highlighted using the circle. The lower quality of the Spline type approximation can be also proven through the values of the Mean Square Errors between the values of the $S_{F S T}\left(F_{f}\right)$ respectively, of the $S_{P S T}\left(F_{i}\right)$ functions and the values of the responses of the associated Spline type, respectively, neural approximations. In Table 8 , 
the centralizer containing the computed MSE values is presented. In order to compute the MSE for 1251 pairs of values, the same samples of the $S_{P S T}\left(F_{i}\right)$ and the $S_{F S T}\left(F_{f}\right)$ functions are used as in the case of the polynomial approximation. Consequently, the MSE values associated to the neural approximation (computed for 1251 pairs of values) are presented in Table 5, as well. In the case of computing the MSE for 25 pairs of values, the 25 subintervals associated to the procedure of determining the Spline type approximation, are considered.

Table 8. Centralizer with MSE Values.

\begin{tabular}{|c|c|c|c|c|c|c|c|c|}
\hline \multirow{3}{*}{$\begin{array}{c}\text { Considered Function } \\
\text { Model Type } \\
\text { Number of Considered Points } \\
\end{array}$} & \multicolumn{4}{|c|}{$S_{P S T}\left(F_{i}\right)$} & \multicolumn{4}{|c|}{$S_{F S T}\left(F_{f}\right)$} \\
\hline & \multicolumn{2}{|c|}{ Spline } & \multicolumn{2}{|c|}{ Neural } & \multicolumn{2}{|c|}{ Spline } & \multicolumn{2}{|c|}{ Neural } \\
\hline & 25 & 1251 & 25 & 1251 & 25 & 1251 & 25 & 1251 \\
\hline $\begin{array}{l}\text { MSE value computed in relation } \\
\text { to the } S_{P S T}\left(F_{i}\right) \text { respectivelyto the } \\
S_{F S T}\left(F_{f}\right) \text { functions values }\end{array}$ & $6.81 \times 10^{-2}$ & $5.32 \times 10^{-2}$ & $6.99 \times 10^{-5}$ & $7.91 \times 10^{-4}$ & $2.43 \times 10^{-2}$ & $1.89 \times 10^{-2}$ & $2.72 \times 10^{-5}$ & $5.73 \times 10^{-4}$ \\
\hline
\end{tabular}

In the case of each function $S_{P S T}\left(F_{i}\right)$, respectively, $S_{F S T}\left(F_{f}\right)$ and in the case of all associated approximating functions (neural and Spline types), for the MSE computation, their values at the center of each subinterval are considered (the centers of the 25 intervals are considered in relation to $F_{i}$ and $F_{f}$ input signals; in the case of the general notation, the center of each subinterval is the average value $\left.z_{a v}=\left(z_{i}+z_{i+1}\right) / 2\right)$. This aspect is due to the fact that, for the Spline approximation, the accuracy cannot be highlighted by computing the MSE in the interpolation points, because it would result in the value $M S E=0$. This is because in (22), $d_{i}=f_{i}(i \in\{1,2,3, \ldots \ldots, n-1\})$. Obviously, the $M S E=0$ value is not a realistic one after analyzing Figure 7.

From Table 8, it results that in both the $S_{P S T}\left(F_{i}\right)$ and the $S_{F S T}\left(F_{f}\right)$ functions and for both two methods of computing MSE, the neural approximation generates a much better accuracy. Moreover, from Figure 7 , it results that the highest error between the $S_{F S T}\left(F_{f}\right)$ function and the associated Spline type approximation occurs for $F_{f}=141.9 \mathrm{~L} / \mathrm{h}$, having the value $E_{2}=0.096$ (absolute value). Considering these values of the input signals $\left(F_{i}=1807.4 \mathrm{~L} / \mathrm{h}\right.$ and $\left.F_{f}=141.9 \mathrm{~L} / \mathrm{h}\right)$, the comparative graph between the most probable response of the separation cascade and the responses of the separation cascade models using the Neural Networks, respectively, the Spline types of approximation (simultaneously, for both $S_{P S T}\left(F_{i}\right)$ and $S_{F S T}\left(F_{f}\right)$ functions, the same approximation type is used), is presented in Figure 8. In Figure 8, it is obvious that, using the neural approximation for the $S_{P S T}\left(F_{i}\right)$ and for the $S_{F S T}\left(F_{f}\right)$ functions, the mathematical model of the separation cascade is much more precise than in the case of using the Spline type approximations (the dashed red curve is almost perfectly superposed over the continuous blue one; at the same time the green curve presents a consistent deviation in relation to the other two curves). This happens because, for $F_{i}=1807.4 \mathrm{~L} / \mathrm{h}$ and $F_{f}=141.9 \mathrm{~L} / \mathrm{h}$, the errors between the $S_{P S T}\left(F_{i}\right)$, respectively, the $S_{F S T}\left(F_{f}\right)$ functions and the responses of their neural approximations are proportional with $10^{-4}$. The better performance of the proposed neural models can be proven through the MSE values, too. Hence, 3001 pairs of samples of the curves from Figure 8 are considered, by applying the same sampling time $\Delta T_{S}=1 \mathrm{~h}$ as in the case of the simulations from Figure 6. After computation, between the red and the blue curve from Figure 8 , the value $M S E=0.0035 \%$ is obtained, which is much lower than the value $M S E=0.6294 \%$ computed between the green and the blue curves from Figure 8 . 


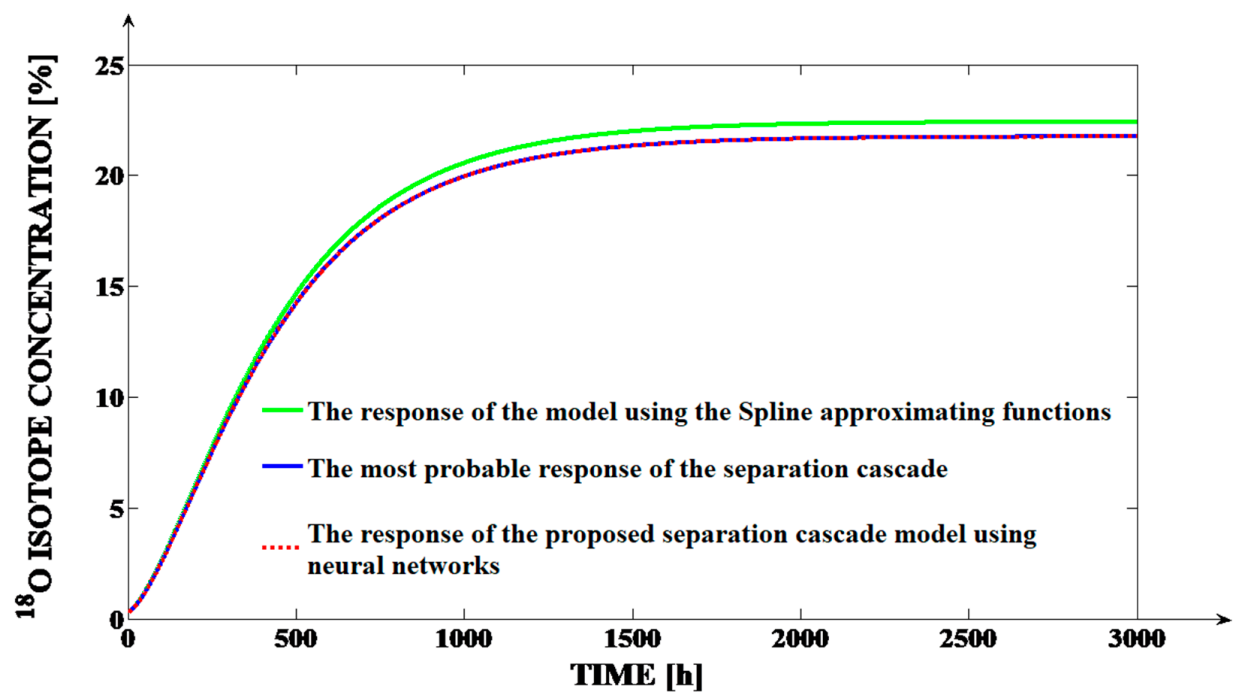

Figure 8. The effect of the $S_{P S T}\left(F_{i}\right)$ and of the $S_{F S T}\left(F_{f}\right)$ functions approximation, using neural networks, respectively, the Spline functions.

Consequently, the MSE obtained in the case of using the neural approximations is more than 100 times smaller than the MSE obtained in the case of Spline type approximations. Moreover, the error value of $0.0035 \%$ is considered to be insignificant for the isotope separation applications, but the error value of $0.6294 \%$ is a "huge" one for these types of applications and it is considered unacceptable. Additionally, in a steady-state regime, the deviation of the red curve in relation to the blue curve is only of $4 \times 10^{-3} \%$ (an insignificant value), but the deviation of the green curve in relation to the blue curve is of $0.6631 \%$ (an unacceptable deviation).

In contrast to the polynomial type of approximation, if, in the case of the Spline function, the number of the interpolation points is consistently increased, the accuracy of the approximation can be significantly increased. Hence, in order to obtain approximately the same accuracy as in the case of using the neural solutions, the number of the interpolation points must be increased to 187 . The main problem in this case is the fact that a total of 744 parameters of the Spline function result (4 parameters for each of 186 resulted subintervals), a value much higher than 36 (the average number of parameters of the neural solution used for modeling one of the 3 modeled functions).

Another important problem refers to the $T_{1}\left(F_{i}\right)$ and $T_{2}\left(F_{f}\right)$ functions approximation. These functions do not present a monotony change, an aspect which implies the fact that the approximation of their behavior is simpler than in the cases of the $S_{P S T}\left(F_{i}\right)$ and the $S_{F S T}\left(F_{f}\right)$ functions. Consequently, the polynomial approximation is tested and the $T_{2}\left(F_{f}\right)$ function is considered as a case study. In this context, a 25th degree polynomial with the structure presented in (21) is used, and the same procedure for determining the polynomial coefficients is applied.

The higher accuracy of the neural model is proven through the MSE values between the resulted responses. Hence, considering 1251 samples of the curves, the MSE obtained between the responses of the neural model and the identified function is $6.46 \cdot 10^{-5} \mathrm{~h}$, and the MSE obtained between the responses of the polynomial model and the identified function curve is $8.48 \times 10^{-5} \mathrm{~h}$. It results that the neural model generates a sensible higher accuracy than the polynomial model. The same conclusion results in the case of the approximation of $T_{1}\left(F_{i}\right)$ function (using a 25th degree polynomial and the NNPSC). Consequently, in the cases of the $T_{1}\left(F_{i}\right)$ and $T_{2}\left(F_{f}\right)$ functions, considering the fact that the neural solutions generate sensible better solutions than the polynomial ones, but the polynomial approximations have a smaller number of parameters than the neural ones (each polynomial presents 26 coefficients, a smaller number than 36 average parameters of each neural solution), the usage of the two approximating models imply the same 
degree of advantage. In this context, the analysis of the Spline type approximation is no longer necessary.

In the case of the $R_{1}\left(F_{i}\right)$ and the $R_{2}\left(F_{f}\right)$ functions approximation, the problem is more complicated than in the case of the $T_{1}\left(F_{i}\right)$ and $T_{2}\left(F_{f}\right)$ functions approximation, because they present a monotony variation. In this context, the usage of the polynomial approximation is not efficient due to the same explanations as in the case of the $S_{P S T}\left(F_{i}\right)$ and $S_{F S T}\left(F_{f}\right)$ functions. Using the same procedure as in the case of the $S_{P S T}\left(F_{i}\right)$ and $S_{F S T}\left(F_{f}\right)$ functions, it can be proven that the neural approximation of the $R_{1}\left(F_{i}\right)$ and the $R_{2}\left(F_{f}\right)$ functions generates a consistent higher accuracy than the Spline type approximation. Considering the presented study, the following conclusions, which justify the neural network usage as modeling solution, result:

1. NNPSC and NNFSC represent unitary models, which (each) learn the behavior of three functions (simultaneously), by applying the Levenberg-Marquardt learning algorithm;

2. The accuracy generated by NNPSC and NNFSC is much higher in the case of learning the behavior of $S_{P S T}\left(F_{i}\right), S_{F S T}\left(F_{f}\right), R_{1}\left(F_{i}\right)$, and $R_{2}\left(F_{f}\right)$ functions, respectively, it is sensibly higher in the case of learning the behavior of $T_{1}\left(F_{i}\right)$ and $T_{2}\left(F_{f}\right)$ functions; this remark is valid comparing the two neural models with the polynomial, respectively, the Spline models;

3. The higher accuracy generated by NNPSC and NNFSC is obtained using much fewer parameters than in the cases of the polynomial and the Spline functions; hence, NNPSC and NNFSC each use 108 weights and bias values; it results in an average number of 36 parameters used for each function learning (both NNPSC and NNFSC learn 3 functions simultaneously);

4. The best solution of using the polynomial approximations implies the use of 128 parameters for modeling the group of functions $\left(S_{P S T}\left(F_{i}\right) ; T_{1}\left(F_{i}\right) ; R_{1}\left(F_{i}\right)\right)$ and of other 128 for modeling the group of functions $\left(S_{F S T}\left(F_{f}\right) ; T_{2}\left(F_{f}\right) ; R_{2}\left(F_{f}\right)\right)$; for example, in the case of the group of functions $\left(S_{P S T}\left(F_{i}\right) ; T_{1}\left(F_{i}\right) ; R_{1}\left(F_{i}\right)\right)$, the polynomial that models the $S_{P S T}\left(F_{i}\right)$ function contains 51 coefficients, the polynomial that models the $T_{2}\left(F_{f}\right)$ contains 26 coefficients, and the polynomial that models the $R_{1}\left(F_{i}\right)$ function contains 51 coefficients; the main problems of the polynomial models is the fact that they cannot model with an acceptable accuracy the $S_{P S T}\left(F_{i}\right), S_{F S T}\left(F_{f}\right), R_{1}\left(F_{i}\right)$ and $R_{2}\left(F_{f}\right)$ functions;

5. The sufficient solution for using the Spline functions, which generate approximately the same accuracy as NNPSC and NNFSC, imply the usage of 1644 parameters for modeling the group of functions $\left(S_{P S T}\left(F_{i}\right) ; T_{1}\left(F_{i}\right) ; R_{1}\left(F_{i}\right)\right)$ and of other 1644 for modeling the group of functions $\left(S_{F S T}\left(F_{f}\right) ; T_{2}\left(F_{f}\right) ; R_{2}\left(F_{f}\right)\right)$; for example, in the case of the group of functions $\left(S_{P S T}\left(F_{i}\right) ; T_{1}\left(F_{i}\right) ; R_{1}\left(F_{i}\right)\right)$, the Spline function that models the $S_{P S T}\left(F_{i}\right)$ function contains 744 coefficients, the Spline function that models the $T_{2}\left(F_{f}\right)$ contains 208 coefficients, and the Spline function that models the $R_{1}\left(F_{i}\right)$ function contains 692 coefficients; consequently, the main problem of the Spline functions is the extremely high number of coefficients that have to be used in order to generate the same accuracy as the neural models; hence, the numerical implementation of Spline functions is very difficult due to the large number of parameters and consequently the resulted large dimensions of the corresponding look-up tables;

6. The three types of approached methods of the approximation (neural, polynomial, and Spline type) were tested in the most unfavorable conditions; both on the entire range of input signals values and in the most unfavorable conditions, the neural networks generated the highest accuracy;

7. The most consistent advantage of using the neural approximations, from the accuracy perspective, is obtained for the learning of the $S_{P S T}\left(F_{i}\right)$ and the $S_{F S T}\left(F_{f}\right)$ functions; these two functions have the most important influence over the separation cascade model's accuracy;

8. Considering all the above, we may conclude that the use of NNPSC and NNFSC is recommended in the separation cascade model, giving us the possibility of using the model in future control applications. 


\subsection{Proof of Neural Model Practical Feasibility}

The proposed model of the separation cascade operation can be used in future applications, for example, as a reference model in a complex control structure (which implements for example the Internal Model Control strategy). In this context, better performances of the future proposed control systems designed for controlling the product concentration (the extracted ${ }^{18} \mathrm{O}$ isotope concentration) are obtained if the reference model is more accurate. Initially, the proposed model, using the neural approximations, presented (as it was previously proven) a high level of accuracy. However, during a long period of operation, the structure parameters of the separation cascade, due to multiple technological reasons, presented variations in relation to time. In this context, the necessity to implement an adaption algorithm to modify the initial model by adapting it to describe with high accuracy, where the instantaneous behavior of the separation cascade occurred. The most feasible and efficient solution for the adaption algorithm implementation is to use the neural models (NNPSC and NNFSC) and to modify, after the online adaption law, the values of the elements of the $\mathrm{B}_{\mathrm{OLj}}$ vectors from (30) and (31). For a consistent range of the physical variations of the separation cascade structure parameters, the proposed model can be adapted with high accuracy. Hence, the effects of the parametric disturbances are efficiently rejected. As an important remark, the other types of the approached modeling solutions (polynomial and Spline type) were not feasible to be integrated in an adaption mechanism.

\subsection{Proof of Neural Model Feasibility in Future Applications}

Due to the approached separation process complexity and due to the necessity of the future implemented control systems (for controlling the ${ }^{18} \mathrm{O}$ isotope concentration) to gentableerate high control performances (both from technological and from economic reasons), the intelligent control figure usage becomes feasible and necessary. In practice, many intelligent control strategies are based on using the neural networks [67-70]. Consequently, the necessity to train neural controllers occurs. For training the neural controllers, the same learning algorithm (Levenberg-Marquardt), as is used in the case of training the NNPSC and NNFSC, can be applied, resulting in the advantage of using the implemented learning algorithm for obtaining the separation cascade model, for training future neural controllers. The unitary approach for determining the parameters of the separation process model and the parameters of the future controllers (using neural networks and using the same learning algorithm) significantly reduces the data processing volume.

\subsection{Strategies for the Adaptive Learning of the Separation Cascade Behavior}

An important future research direction which will be approached soon is represented by the online identification of the separation cascade instantaneous mathematical model.

(a) Prove the feasibility of online adapting the proposed model.

During the operation, some of the structure parameters of the separation cascade can present variations in relation to time, resulting in the necessity of adapting the initial form of the proposed model. Next, the case of the variation of the parameters of the $\operatorname{HETP}_{1}\left(F_{i}\right)$ function from (3) is presented (for example, $\mathrm{HETP}_{1 \mathrm{C}}, \mathrm{K}_{\mathrm{H} 10}$, or / and $\mathrm{K}_{\mathrm{H} 20}$ ), a variation that has as an effect, the increase in this function and implicitly the decrease in the $S_{P S T}\left(F_{i}\right)$ function. The online adapting of the proposed model to these possible variations can be made by using the Adaptive Mechanism from Figure 9. 


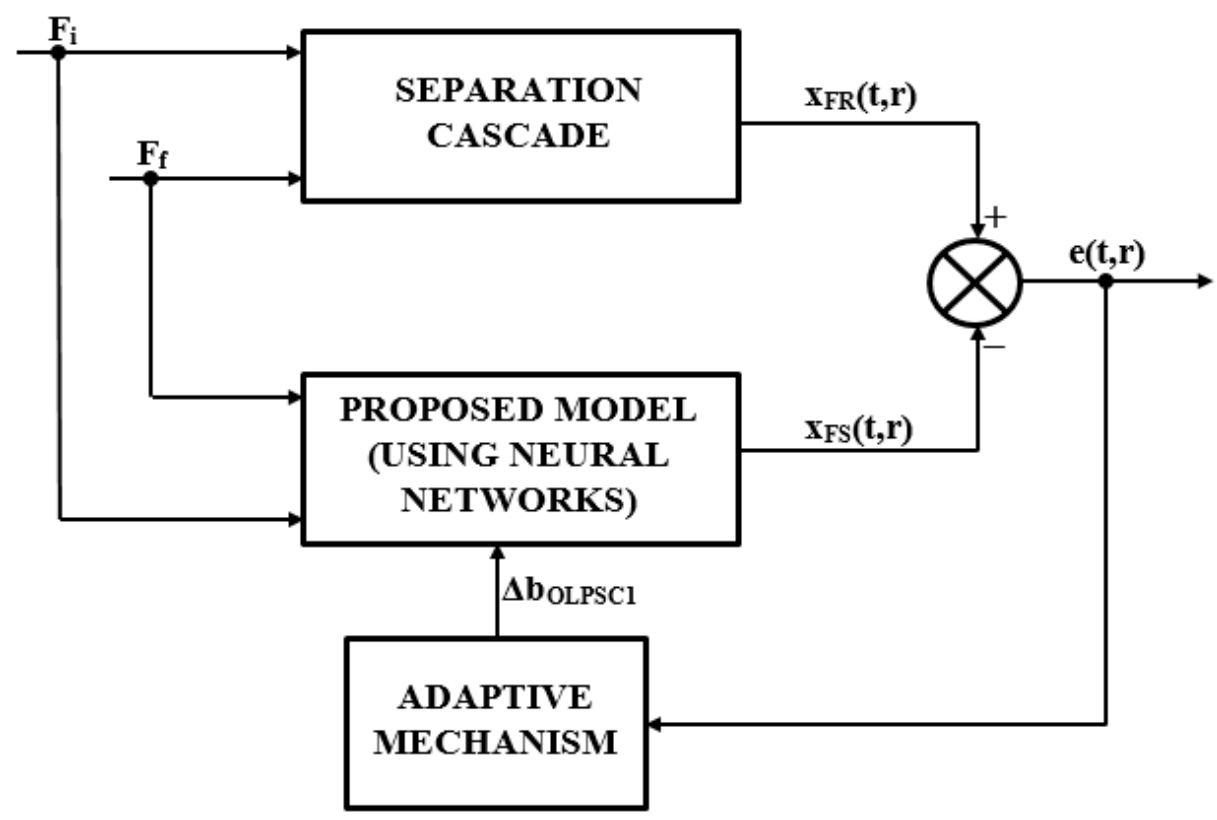

Figure 9. The usage of the Adaptive Mechanism.

In Figure 9, the proposed model based on the usage of the neural networks is run in parallel with the real separation process, the same input signals $\left(F_{i}\right)$ and $\left(F_{f}\right)$ being applied to the input of both entities. In this figure, the notation $x_{F R}(t, r)$ is referring to the real concentration of the ${ }^{18} \mathrm{O}$ isotope at the output from FSC, and the notation $x_{F S}(t, r)$ is referring to the simulated concentration of the ${ }^{18} \mathrm{O}$ isotope at the output from FSC, obtained by simulating the proposed mathematical model. The difference between the two signals gives the error signal $e(t, r)$. The error signal is applied at the input of the Adaptive Mechanism, which processes its value and generates the adaptation signal. Analyzing Figure 2, the $S_{P S T}\left(F_{i}\right)$ function approximation is generated by NNPSC at the output of the $\mathrm{NO}_{\mathrm{PSC} 1}$ neuron, results. Consequently, a direct solution for adapting the proposed model to the variation of the mentioned structure parameters is to adapt the bias value of the $\mathrm{NO}_{\mathrm{PSC} 1}$ neuron $\left(b_{\mathrm{OLPSC}}\right)$. In this context, after processing the error value, the Adaptive Mechanism generates the adaptation signal $\left(\triangle b_{O L P S C 1}\right)$, which is added to the initial $\left(b_{O L P S C}\right)$ bias value.

In the approached particular case, the Adaptive Mechanism is implemented by using a PI (Proportional Integral) controller.

In Figure 10, the effects of the variation of the mentioned structure parameters (which are due to some parametric disturbances) and of the proposed adaptive strategy are presented in a comparative manner.

The effect of the parametric disturbances occurrence is visible through the decrease in the ${ }^{18} \mathrm{O}$ isotope concentration at the FSC output due to the decrease in the $S_{P S T}\left(F_{i}\right)$ function. Additionally, due to the effect of the adaptation (visible after the moment $t=2500 \mathrm{~h}$ when the parametric disturbances occur in the process), the model output signal (the approximated ${ }^{18} \mathrm{O}$ isotope concentration at the FSC output) tracks with precision the most probable response of the separation cascade (in the case when it is affected by the parametric disturbances).

An important stage in proving the validity of the proposed adaptive strategy is it testing at the variation of the input flows. This aspect is highlighted in Figure 11. 


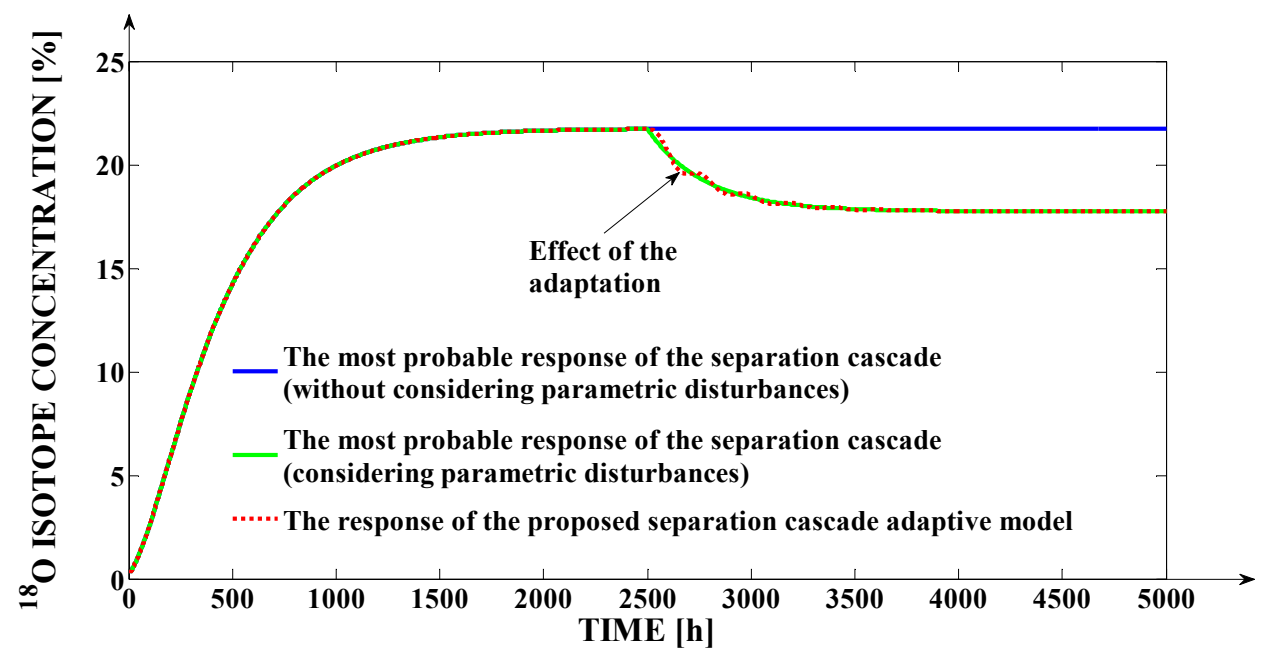

Figure 10. The effect of the parametric disturbances and the effect of the proposed adaptive strategy.

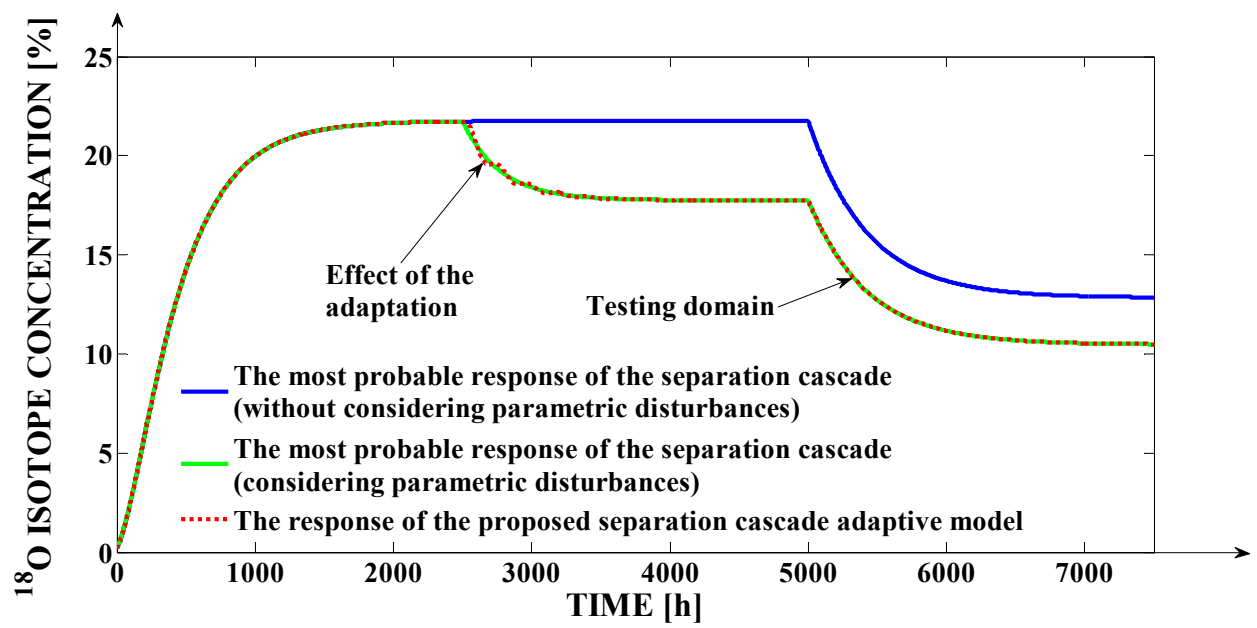

Figure 11. Testing the proposed adaptive strategy.

An important remark is the fact that the simulations presented in Figure 10 and the simulations presented in the first $5000 \mathrm{~h}$ of Figure 11 are made using the same input flows as in the case of Figure 8. In Figure 11, after the first $5000 \mathrm{~h}$, a variation of the $\left(F_{f}\right)$ input flow with $40 \mathrm{~L} / \mathrm{h}$ is considered. From this figure, the proposed adaptive strategy is an efficient one, results, since after the moment $t=5000 \mathrm{~h}$, the proposed mathematical model response remains superposed over the most probable response of the separation cascade (in the case of the parametric disturbances persistence).

The variation, in relation to time, of the $\left(b_{O L P S C 1}\right)$ bias value is presented in Figure 12. The adaptation effort is visible after the moment $t=2500 \mathrm{~h}$. Further, after the moment $t=5000 \mathrm{~h}$, the $\left(b_{O L P S C}\right)$ bias value remains constant because the ${ }^{18} \mathrm{O}$ isotope concentration at the output of FSC is due to the $\left(F_{f}\right)$ input signal variation and not due to a parametric disturbance. 


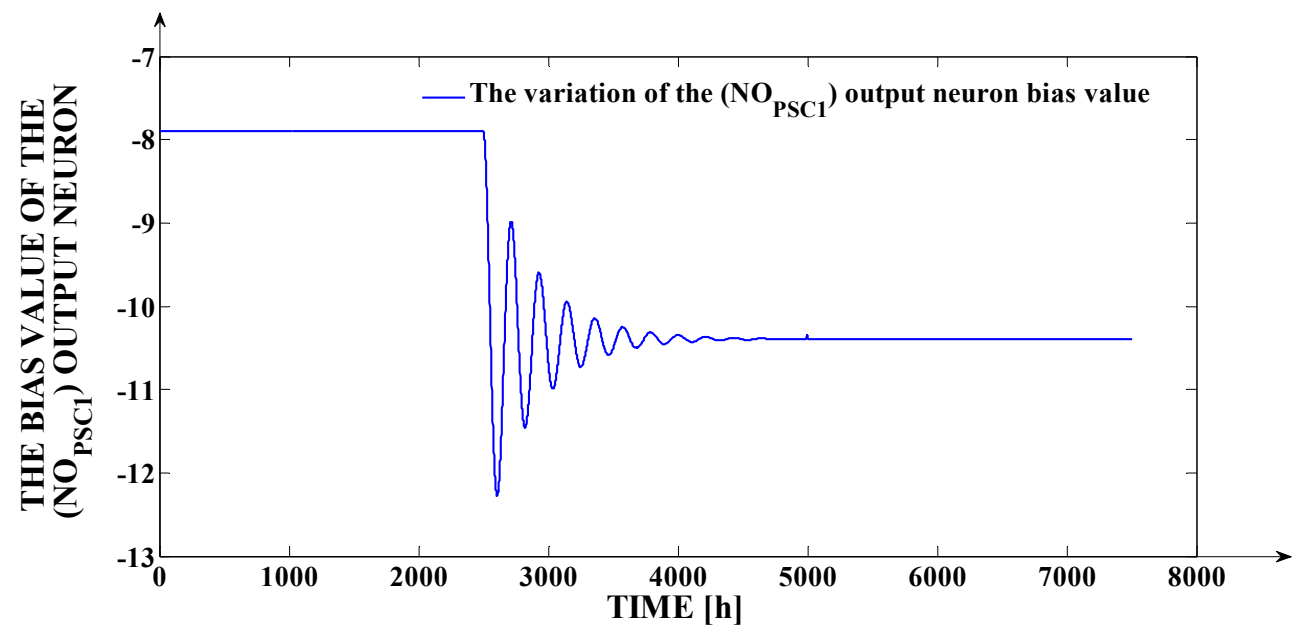

Figure 12. The variation, in relation to time, of the $\left(b_{O L P S C 1}\right)$ bias value.

(b) The idea of the adaptive strategy generalization.

In near future, the problem of the proposed adaptive strategy generalization will be approached. The generalized adaptive strategy will contain in the structure the following elements:

- A Decision Element, which will have the purpose of identifying the structure parameters that present variations in relation to time; in the presented example, only the variation of the $S_{P S T}\left(F_{i}\right)$ function was considered as a consequence of the variation of one or more $\operatorname{HETP}_{1}\left(F_{i}\right)$ function parameters, but during the real operation of the plant, other structure parameters can present variations, too (for example, the separation process time constants $T_{1}\left(F_{i}\right)$ and $T_{2}\left(F_{f}\right)$ or "length constants" $R_{1}\left(F_{i}\right)$ and $R_{2}\left(F_{f}\right)$ ); these variations of the different separation process structure parameters can also occur, simultaneously; consequently, the identification of the process structure parameters that are affected by the parametric disturbances become necessary in order to determine which weights or bias values of the two used neural networks have to be modified as result of the adaptation effect;

- The Adaptive Mechanism, which will have the same main purpose as in Figure 9, but which will run more complex optimization algorithms (the Adaptive Mechanism will have to generate more than one adaptation signals); the Adaptive Mechanism can be implemented, also, by using AI specific methods;

- A Signal Distributor which will have the purpose to distribute the adaptation signals generated by the Adaptive Mechanism to the two neural networks weights and bias values; the identification of the weights and bias values of the two neural networks, which must be modified to adapt the proposed mathematical model properly, is also made by the Adaptive Mechanism.

(c) The real-time identification of the separation model.

Another future possibility for obtaining the adapted mathematical model of the separation cascade is represented by the real-time learning of the process behavior. In this case, the following stages must be passed through:

- The input and the output signals corresponding to the separation cascade, after their measuring and sampling, are be saved as datasets;

- The resulting datasets are preprocessed;

- In the case of identifying deviations of the proposed model response from the real response of the separation cascade, the two neural networks are trained again using the mentioned datasets;

- The old neural solutions will be replaced with the new ones, obtained at the previous stage. 
As a conclusion, the mathematical model adaptation at the occurrence of the parametric disturbances is very important due to the necessity of using it with high precision in different applications (as reference model in automatic control structure, as model for approximating the separation cascade energy consumption, as decision support for the operators, etc.)

\subsection{Comparison of the Efficiency of Using Two SISO Neural Models and One MIMO Neural Model}

In Figure 2, the structure of the two SISO (Single Input Single Output) used neural networks is presented (" $\mathrm{j}$ " referring to PSC or FSC). Consequently, the instantaneous values of the $S_{P S T}\left(F_{i}\right), T_{1}\left(F_{i}\right)$, and $R_{1}\left(F_{i}\right)$ functions are generated by NNPSC, respectively, the instantaneous values of $S_{F S T}\left(F_{f}\right), T_{2}\left(F_{f}\right)$, and $R_{2}\left(F_{f}\right)$ and functions are generated by NNFSC.

Another possibility to generate the six mentioned functions is based on using a MIMO neural model, having the general structure from Figure 13.

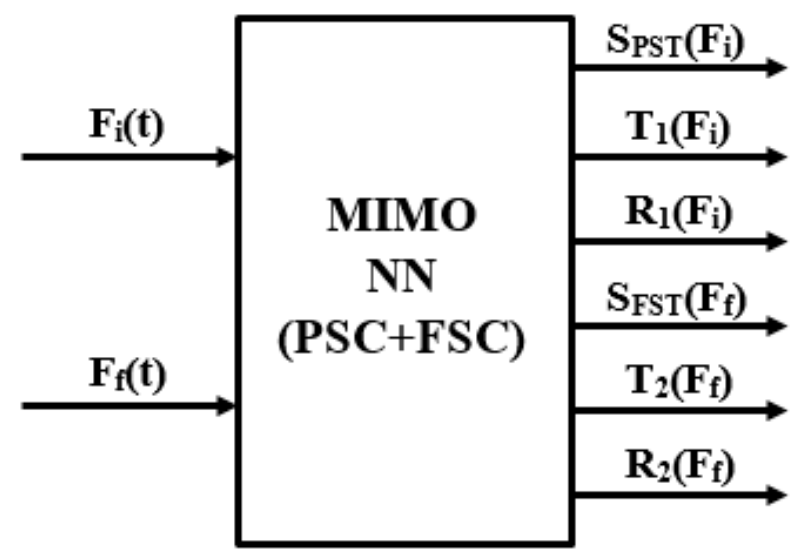

Figure 13. The structure of the MIMO neural network.

Figure 13 highlighted the fact that the considered MIMO Neural model has two input signals $\left(F_{i}\right.$ and $\left.F_{f}\right)$, respectively, and six output signals $\left(S_{P S T}\left(F_{i}\right), T_{1}\left(F_{i}\right), R_{1}\left(F_{i}\right), S_{F S T}\left(F_{f}\right)\right.$, $T_{2}\left(F_{f}\right)$, and $R_{2}\left(F_{f}\right)$ ). The MIMO neural network from Figure 13 (MIMO NN) is, also, a feedforward fully connected one. In this context, the two input signals are applied through the corresponding weights to each neuron from the hidden layer and the output layer contains six linear neurons. The neurons from the hidden layer are, in this case too, nonlinear, having hyperbolic tangent transfer function. The training procedure applied for training the MIMO NN, the training parameters, the used training datasets, and the used testing datasets were the same as in the cases of NNPSC and NNFSC (with the remark that the input-output datasets were used properly for the sizes of the input and output layers). The best results were obtained in the case of using 29 neurons in the hidden layer. After the training process, the obtained MIMO neural solutions were tested by computing the MSE value corresponding to each output signal; the obtained values are centralized in Table 9.

Table 9. Centralizer with MSE Values Associated to the MIMO NN Neural Model.

\begin{tabular}{|c|c|c|c|c|c|c|}
\hline Neural Network & & NNPSC & & & NNFSC & \\
\hline $\begin{array}{c}\text { Considered Output from } \\
\text { MIMO NN }\end{array}$ & $S_{P S T}\left(F_{i}\right)$ & $T_{1}\left(F_{i}\right)$ & $R_{1}\left(F_{i}\right)$ & $S_{F S T}\left(F_{f}\right)$ & $T_{2}\left(F_{f}\right)$ & $R_{2}\left(F_{f}\right)$ \\
\hline $\begin{array}{l}\text { MSE between the MIMO NN } \\
\text { output values and the real } \\
\text { function values }\end{array}$ & $9.78 \times 10^{-4}$ & $1.17 \times 10^{-4}$ & $1.04 \times 10^{-2}$ & $2.5 \times 10^{-3}$ & $2.72 \times 10^{-4}$ & $1.85 \times 10^{-2}$ \\
\hline
\end{tabular}

After making the comparison between the results obtained in Table 9 and the results obtained in Table 4, we note that the computed MSE values were higher in the case of 
using the MIMO NN structure. Consequently, the accuracy generated by the two SISO neural structures is better than the accuracy generated the MIMO NN structure. However, because, in both cases, the MSE values are very small ones (lower or much lower than $\left.10^{-1}\right)$, it is important to highlight the effective advantage introduced by the usage of two SISO neural models.

The comparative graph between the most probable response of the separation cascade and the response of the proposed model implemented by using a MIMO neural network, is presented in Figure 14.

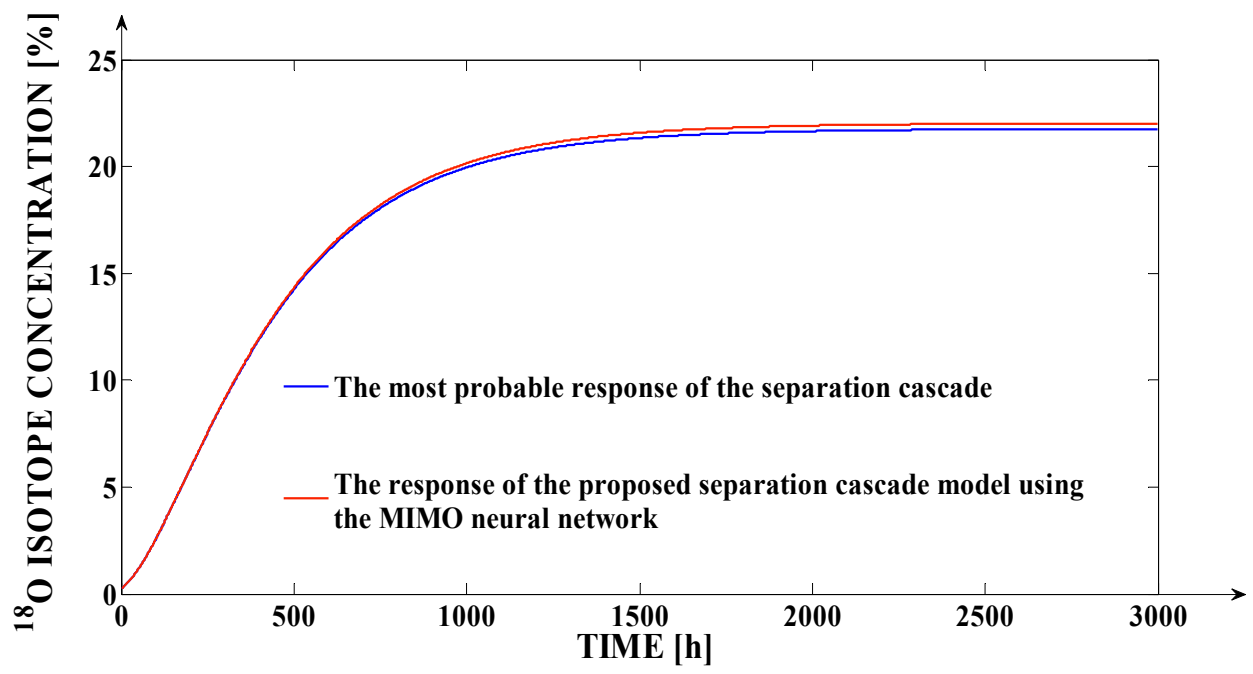

Figure 14. The performances generated by using the MIMO NN neural structure.

The responses from Figure 14 are obtained using the same input flows as in the case of Figure 8. Considering the same sampling time and the same number of pair of samples of the curves from Figure 14, as in the case of Figure 8, the value $M S E=0.2152 \%$ is obtained. This value is consistently higher than the value $0.0035 \%$, obtained in the case of using two SISO neural models (this error was computed above for the analysis of Figure 8). Consequently, for the considered mathematical modelling application, the accuracy of the separation cascade model implemented using two SISO neural networks generates a consistently higher accuracy than the separation cascade model implemented using one MIMO neural network (aspect visible directly in Figure 14). This aspect is due, mainly, to the better approximation of the $S_{P S T}\left(F_{i}\right)$ and $S_{F S T}\left(F_{f}\right)$ functions by using two SISO neural networks rather than in the case of using one MIMO neural network, which is a direct consequence of a better approximation of the $\operatorname{HETP}_{1}\left(F_{i}\right)$ and of the $\operatorname{HETP}_{2}\left(F_{f}\right)$ functions.

On the other hand, the separation cascade model implemented based on usage of only one MIMO neural network generates much better performances than in the case of using the polynomial approximation or the Spline type functions. This conclusion results directly by comparing the simulation from Figure 14 with the simulations presented in Figures 6 and 8 , but, also, by comparing the MSE values obtained in Table 9 with the corresponding values presented in Tables 6 and 8. Consequently, the better performances generated by the neural models for the considered mathematical modelling application is proved again.

The high accuracy of the proposed mathematical model is vital for using it in future applications of automatic control of the ${ }^{18} \mathrm{O}$ isotope concentration and for reducing the energy consumption of the separation plant. This remark is strengthened by the fact that the separation cascade is an extremely slow process and small quantities of the product are obtained in long periods of time. 


\section{Conclusions}

The usage of neural networks in learning the dynamic of the separation cascade structure parameters, in relation to the input flows in the two separation columns, contributes significantly to the model's high accuracy, the neural networks generating a higher precision than other modeling techniques.

Section 4 proves the necessity to use neural networks to obtain an accurate model of the ${ }^{18} \mathrm{O}$ isotope separation cascade operation.

There are two possibilities to connect two or more separation columns in order to increase the concentration of the separated isotope. The first applicable possibility is the serial connection of the separation columns. In this case, two or more separation columns are used, having the same size (as height and section area) and all being supplied with the same input flow of the chemical substance, which implies the occurrence of the separation phenomenon (the input flow in the first column, which is also the input flow in the entire serial separation structure, is equal to the input flows in each separation column from the serial structure). Moreover, the input flow for each column from the serial structure (except the first one) corresponds with the output flow from the immediate previous one. Practically, the serial structure substitutes one equivalent separation column that has the same section area as all the columns from the mentioned serial structure, having the height equal to the sum of their heights. The advantage of using the serial connection of the separation columns is the fact that the separation plant can operate in industrial halls of usual height (in contrast to the case of one equivalent separation column which a consistent higher height). The second applicable possibility is the cascade type connection of the separation columns. The separation cascade represents a structure that contains two or more separation columns, in general having the same height, but having different sections areas. Moreover, the section area decreases from the first column from the cascade to the last one. An important aspect is the fact that each column from the cascade (excepting the last one) supplies the immediate consecutive column. Another important aspect is represented by the fact that the supplying flow of each column from the cascade structure decreases from the first column to the last one. Practically and physically, the next column from the cascade structure separates the isotope already separated by the previous one. Consequently, the cascade separation strategy is more efficient than the serial connection strategy. In the case of the approached example, a particular case of a separation cascade, containing two separation columns in its structure, is considered. Compared with the case of the separation serial structure, the separation cascade generates a higher separation (and implicitly the obtained separated isotope concentration is higher), but it is more difficult to be implemented as sizing.

The paper approaches, as a case study, the problem of modeling and simulation of the ${ }^{18} \mathrm{O}$ isotope separation process. Basically, the proposed method for modeling the operation of each separation column can be adapted for other separation processes (for example, for the separation of the ${ }^{13} \mathrm{C},{ }^{10} \mathrm{~B}$, and ${ }^{15} \mathrm{~N}$ isotopes). In this context, there are some common elements that allow the modeling procedure adaption from the case of ${ }^{18} \mathrm{O}$ isotope separation to the cases of other isotopes separation, elements such as:

- All the separation processes associated to the separation columns are distributed parameter ones, the separated isotope concentration depending both on the time independent variable and on the position in the separation column (especially in relation to the column height);

- All separation processes are strong nonlinear ones;

- All separation processes are extremely slow processes and the corresponding time constants present consistent variations in relation to the operation intensity of the separation plant;

- The Separation parameter, in different forms, can be highlighted for any separation process;

- Based on consistent experimental data and applying specific or original modeling methods for their processing, the functional variation of the process main structure pa- 
rameters, in relation to the input signal (in general, the input flow for the main chemical substance that allows the separation phenomenon occurrence), can be determined.

Furthermore, there are some consistent differences between the technological procedures used for the separation of different isotopes, differences which can imply complications in the model adaption. Some of these differences, are:

- In the cases of different separation processes, different chemical substances are used (having different properties);

- The operation intensity of the used equipment can present consistent variations from a separation phenomenon to other ones;

- In the cases of different separation processes, different equipment is used;

- The separation plant structure can differ very much from a separation procedure to other ones;

- The Separation parameter, for different cases, can have completely different variation forms than in the case of the presented model.

After adapting the model of each separation column from the separation plant structure, an important stage is the mathematical connection of the resulted models, depending on the type of the columns connection (serial type connection or cascade type connection) in the plant structure.

The processes of separation of stable isotopes on columns with packing differ from one isotope to another by: the elementary separation factor, the speed with which the isotopic exchange between the liquid and the gaseous phase takes place (kinetics of isotopic exchange), the size of fluid flows in countercurrent in the column, the chemical concentration of the liquid phase in chemical equilibrium with the gaseous one, the column temperature and the operating pressure. The proposed model can be successfully applied for other stable isotopes $\left({ }^{15} \mathrm{~N},{ }^{13} \mathrm{C}\right.$, and ${ }^{10} \mathrm{~B}$ ) if the separation process parameters are known (flow rates and nature of fluids in the column, their concentration, operating pressure of the column, working temperature) leading to the determination of the constructive characteristics of the separation cascade (number of columns to achieve a desired separation, height, inside diameter, type of packing in the separation column (stainless steel wire Helipak, Berl ceramic saddles, glass balls, copper wire mesh, and connection mode of columns in series or parallel)).

Author Contributions: Conceptualization, V.M., M.-L.U., M.A. and H.V.; methodology, V.M., M.L.U., M.A., H.V. and I.C.; software, V.M., M.-L.U., M.A., H.V., I.C. and R.M.; validation, V.M., M.A., R.M., E.C. and M.F.; formal analysis, V.M., M.-L.U. and M.A.; investigation, V.M., M.-L.U., M.A., H.V., I.C., R.M., E.C. and M.F.; resources, V.M., M.-L.U., M.A. and H.V.; data curation, V.M., M.A., H.V. and I.C.; writing—original draft preparation, V.M., M.-L.U. and I.C.; writing—review and editing, V.M., I.C. and R.M.; visualization, M.A., I.C., R.M., E.C. and M.F.; supervision, V.M. and M.A.; project administration, V.M., M.-L.U., M.A. and H.V.; funding acquisition, V.M. and H.V. All authors have read and agreed to the published version of the manuscript.

Funding: This research received no external funding.

Institutional Review Board Statement: Not applicable.

Informed Consent Statement: Not applicable.

Data Availability Statement: Not applicable.

Conflicts of Interest: The authors declare no conflict of interest.

\section{References}

1. Xiao, W.; Lee, X.; Wen, X.; Sun, X.; Zhang, S. Modeling biophysical controls on canopy foliage water ${ }^{18} \mathrm{O}$ enrichment in wheat and corn. Glob. Chang. Biol. 2012, 18, 1769-1780. [CrossRef]

2. Durand, J.L.; Bariac, T.; Ghesquière, M.; Biron, P.; Richard, P.; Humphreys, M.; Zwierzykovski, Z. Ranking of the depth of water extraction by individual grass plants, using natural ${ }^{18} \mathrm{O}$ isotope abundance. Environ. Exp. Bot. 2007, 60, 137-144. [CrossRef] 
3. Nabatame, T.; Yasuda, T.; Nishizawa, M.; Ikeda, M.; Horikawa, T.; Toriumi, A. Comparative Studies on Oxygen Diffusion Coefficients for Amorphous and $\gamma-\mathrm{Al}_{2} \mathrm{O}_{3}$ Films using ${ }^{18} \mathrm{O}$ Isotope. Jpn. J. Appl. Phys. 2003, 42, 7205-7209. [CrossRef]

4. Van Rompay, P.A.; Zhang, Z.; Nees, J.A.; Mourou, G.A.; Pronko, P.P. Angular dependence of isotope enrichment in ultrafast laser ablation plumes. In Proceedings of the Conference on Lasers and Electro-Optics; TOPS: Chiba, Japan, 2001; Volume 56.

5. Axente, D.; Abrudean, M.; Bâldea, A. ${ }^{15} \mathrm{~N},{ }^{18} \mathrm{O},{ }^{10} \mathrm{~B},{ }^{13} \mathrm{C}$ Isotopes Separation Trough Isotopic Exchange; Science Book House: Cluj-Napoca, Romania, 1994; pp. 122-238.

6. Abrudean, M. Isotopic Exchange between $\mathrm{NO}, \mathrm{NO}_{2}$ and $\mathrm{H}_{2} \mathrm{O}, \mathrm{HNO}_{3}$. Ph.D. Thesis, Department State Committee for Nuclear Energy, Physics and Nuclear Engineering Institute, Bucharest, Romania, February 1981.

7. Ching, K.; Baker, A.; Tanaka, R.; Zhao, T.W.; Su, Z.; Ruoff, R.S.; Zhao, C.; Chen, X.J. Liquid-phase water isotope separation using graphene-oxide membranes. Carbon 2021, 186, 344-354. [CrossRef]

8. Mori, S.; Akatsuka, H.; Suzuki, M. Carbon and oxygen isotope separation by plasma chemical reactions in carbon monoxide glow discharge. J. Nucl. Sci. Technol. 2001, 38, 850-858. [CrossRef]

9. Li, H.L.; Ju, Y.L.; Li, L.J.; Xu, D.G. Separation of isotope C-13 using high-performance structured packing. Chem. Eng. Process 2010, 49, 255-261. [CrossRef]

10. Naseri, F.; Ali Faal Rastegar, S.; Salek, N.; Charkhi, A.; Yadollahi, A. Effective isolation of europium impurities from 153Sm using electro amalgamation approach based on response surface methodology. Sep. Purif. Technol. 2021, 279, 119701. [CrossRef]

11. Suryanarayana, M.V.; Sankari, M. Laser isotope separation of 176Lu through off-the-shelf lasers. Sci. Rep. 2021, 11, 18292. [CrossRef]

12. Matecha, R.M.; Capo, R.C.; Stewart, B.W.; Thompson, R.L.; Hakala, J.A. A single column separation method for barium iso-tope analysis of geologic and hydrologic materials with complex matrices. Geochem. Trans. 2021, 22, 4. [CrossRef]

13. Niechciał, J.; Kempiński, W.; Stobiński, L.; Trybuła, Z.; Banat, P.; Chorowski, M.; Poliński, J.; Chołast, K.; Kociemba, A. Separation of $3 \mathrm{He}$ isotope from liquid helium with the use of entropy filter composed of carbon nanotubes. Energies 2021, 14, 6832. [CrossRef]

14. Tamburini, F.; Pistocchi, C.; Helfenstein, J.; Frossard, E. A method to analyse the isotopic composition of oxygen associated with organic phosphorus in soil and plant material. Eur. J. Soil Sci. 2018, 69, 816-826. [CrossRef]

15. Lakshmi, D.; Akhil, D.; Kartik, A.; Gopinath, K.P.; Arun, J.; Bhatnagar, A.; Rinklebe, J.; Kim, W.; Muthusamy, G. Artificial intelligence (AI) applications in adsorption of heavy metals using modified biochar. Sci. Total Environ. 2021, 801, 149623. [CrossRef] [PubMed]

16. Masood, A.; Ahmad, K. A review on emerging artificial intelligence (AI) techniques for air pollution forecasting: Funda-mentals, application and performance. J. Clean. Prod. 2021, 322, 129072. [CrossRef]

17. Li, S.; Shen, Y. An approach to simulate gas-solid flow systems with process controllers. Chem. Eng. J. 2022, 429, 132443. [CrossRef]

18. Axente, D.; Abrudean, M.; Bâldea, A.; Calancea, L.; Stroescu, D. The Utilization of ${ }^{18} \mathrm{O}$ Labelled Potassium Phosphate in Studies Concerning Fertilizer Phosphorus Assimilation by Plants. Isot. Isot. Environ. Health Stud. 1979, 15, 312-314. [CrossRef]

19. Abrudean, M.; Axente, D.; Baldea, A. Enrichment of ${ }^{15} \mathrm{~N}$ and ${ }^{18} \mathrm{O}$ by chemical exchange reaction between nitrogen oxide $\left(\mathrm{NO}, \mathrm{NO}_{2}\right)$ and aqueous nitric acid. Isot. Isot. Environ. Health Stud. 1981, 17, 377-382. [CrossRef]

20. Saxena, S.C.; Taylor, T.I. Enrichment of Oxygen-18 by the Chemical Exchange of Nitric Oxide with Nitric Acid Solutions. J. Phys. Chem. 1962, 66, 1480. [CrossRef]

21. Ghate, M.R.; Taylor, T.I. Production of ${ }^{13} \mathrm{C}$ by Chemical Exchange Reaction between Amine Carbamate and Carbon Dioxide in a Solvent-Carrier System. Sep. Sci. 1975, 10, 547-569.

22. Abrudean, M.; Axente, D.; Bâldea, A. Reactor for continuous cracking of the nitric oxide in an electric dischange. Rev. Chim. 1975, $26,485-488$.

23. Jordan, S.; Bonner, F.T. Simultaneous nitrogen and oxygen exchange $\left(\mathrm{NO}-\mathrm{H}_{2} \mathrm{O}\right.$ and $\left.\mathrm{NO}-\mathrm{NO}_{2}-\right)$ between nitric oxide and aqueous solutions of nitrite. Inorg. Chem. 1973, 12, 1363-1369. [CrossRef]

24. Borisov, A.V.; Gvertiteli, I.G.; Kucerov, R.Y. Dritte Arbeitstagung Uber Stabile Isotope, Leipzig 1963; Akademia Verlag: Berlin, Germany, 1965; p. 171.

25. Jiang, Z.; Xu, T.; Mallants, D.; Tian, H.; Owen, D.D.R. Numerical modelling of stable isotope $\left({ }^{2} \mathrm{H}\right.$ and $\left.{ }^{18} \mathrm{O}\right)$ transport in a hydro-geothermal system: Model development and implementation to the Guide Basin, China. J. Hydrol. 2019, 569, 93-105. [CrossRef]

26. Uimanov, I.V.; Shmelev, D.L.; Barengolts, S.A. Simulation of the hydrogen isotope desorption in the cathode spot of a vacuum arc with a ZrDx cathode. In Proceedings of the 2016 27th International Symposium on Discharges and Electrical Insulation in Vacuum (ISDEIV), Suzhou, China, 18-23 September 2016; Volume 1, pp. 1-4.

27. Goldman, M.J.; Vandewiele, N.M.; Ono, S.; Green, W.H. Computer-generated isotope model achieves experimental accuracy of filiation for position-specific isotope analysis. Chem. Geol. 2019, 514, 1-9. [CrossRef]

28. Junbin, Z.; Yong, Q.; Di, H.; Min, X. Extended Isotope Programming Model for Pervasive Computing Environment. In Proceedings of the 2008 Third International Conference on Convergence and Hybrid Information Technology, Busan, Korea, 11-13 November 2008; Volume 1, pp. 94-101.

29. Ana, G.; Niculescu, A.; Bornea, A.; Zamfirache, M.; Draghia, M. TCAP Hydrogen Isotope Separation Process under Development at ICSI Rm. Vâlcea May 2018. IEEE Trans. Plasma Sci. 2018, 46, 2668-2671. [CrossRef] 
30. Truşcă, M.; Albert, Ş.; Soran, M.L.; Varodi, C.; Fărcaş, F.; Ungureşan, M.-L. Application for Some Parameters Monitoring in Installation for Isotopes Separation. In Proceedings of the 2014 IEEE International Conference on Automation, Quality and Testing, Robotics, Cluj-Napoca, Romania, 22-24 May 2014; pp. 499-504.

31. Guyon, F.; Gaillard, L.; Magdas, D.A. Optimization of oxygen-18 ratio measurements by equilibration-Isotope ratio mass spectrometry using various water content matrices. Talanta 2018, 189, 653-656. [CrossRef] [PubMed]

32. Eckel-Passow, J.E.; Mahoney, D.W.; Oberg, A.L.; Zenka, R.M.; Johnson, K.L.; Nair, K.S.; Kudva, Y.C.; Bergen, H.R.; Therneau, T.M. Bi-Linear Regression for ${ }^{18} \mathrm{O}$ Quantification: Modeling across the Elution Profile. J. Proteom. Bioinform. 2010, 3, $314-320$.

33. Kassi, S.; Karlovets, E.V.; Tashkun, S.A.; Perevalov, V.I.; Campargue, A. Analysis and theoretical modeling of the ${ }^{18} \mathrm{O}$ enriched carbon dioxide spectrum by CRDS near $1.35 \mu \mathrm{m}$ : (I) ${ }^{16} \mathrm{O}^{12} \mathrm{C}^{18} \mathrm{O},{ }^{16} \mathrm{O}^{12} \mathrm{C}^{17} \mathrm{O},{ }^{12} \mathrm{C}^{16} \mathrm{O}_{2}$ and ${ }^{13} \mathrm{C}^{16} \mathrm{O}_{2}$. J. Quant. Spectrosc. 2017, 187, 414-425. [CrossRef]

34. Mureşan, V.; Abrudean, M.; Ungureşan, M.-L.; Clitan, I.; Coloşi, T. Control of the ${ }^{18} \mathrm{O}$ isotope separation process. In Proceedings of the 2016 IEEE 11th International Symposium on Applied Computational Intelligence and Informatics (SACI), Timisoara, Romania, 12-14 May 2016; pp. 283-288.

35. Li, H.-X.; Qi, C. Spatio-Temporal Modeling of Nonlinear Distributed Parameter Systems: A Time/Space Separation Based Approach, 1st ed.; Springer: Dordrecht, The Netherlands, 2011; pp. 10-32.

36. Coloşi, T.; Abrudean, M.; Ungureșan, M.L.; Mureșan, V. Numerical Simulation Method for Distributed Parameters Processes Using the Matrix with Partial Derivatives of the State Vector, 1st ed.; Springer Int. Publishing AG: Cham, Switzerland, 2013 ; pp. 1-200.

37. Khalil, H.K. Nonlinear Systems, 3rd ed.; Pearson Education Ltd.: Harlow, UK, 2001; pp. 1-88.

38. Nazir, S.M.; Cloete, J.H.; Cloete, S.; Amini, S. Efficient hydrogen production with $\mathrm{CO}_{2}$ capture using gas switching reforming. Energy 2019, 185, 372-385. [CrossRef]

39. Atabani, A.E.; Rahman, S.; Mekhilef, S. A review on energy saving strategies in industrial sector. Renew. Sustain. Energy Rev. 2011, $15,150-168$.

40. Kim, J.-H.; Seong, N.-C.; Choi, W. Modeling and Optimizing a Chiller System Using a Machine Learning Algorithm. Energies 2019, 12, 2860. [CrossRef]

41. Osuolale, F.N.; Zhang, J. Energy efficiency optimisation for distillation column using artificial neural network models. Energy 2016, 106, 562-578. [CrossRef]

42. Lashkarboluki, R.; Mallah, M.H. A rate-based dynamic model of multicomponent distillation column for ${ }^{18} \mathrm{O}$ isotope separation. Sep. Purif. Technol. 2019, 228, 115745. [CrossRef]

43. Iraola, E.; Nougues, J.M.; Sedano, L.; Feliu, J.A.; Batet, L. Dynamic simulation tools for isotopic separation system modeling and design. Fusion Eng. Des. 2021, 169, 112452. [CrossRef]

44. Secara, M.; Sas, D.M. Mathematical model for ${ }^{18} \mathrm{O}$ separation column based on chemical exchange between nitric oxides and nitric acid solution operated at total reflux. In Proceedings of the 13th International Conference on Engineering of Modern Electric Systems (EMES), Oradea, Romania, 11-12 June 2015.

45. Kemp, R.S. Gas Centrifuge Theory and Development: A Review of U.S. Programs. Sci. Glob. Secur. 2009, 17, 1-19. [CrossRef]

46. Sas, D.M.; Kovendi, Z. Preliminaries in (Mpdx) method associated with Cohen equations. In Proceedings of the IEEE International Conference on Automation, Quality and Testing, Robotics (AQTR), Cluj-Napoca, Romania, 19-21 May 2016.

47. Abrudean, M.; Axente, D.; Bâldea, A.; Jalobeanu, M. Calculation of flows and concentrations of fluids in the separation plant by isotopic exchange $\mathrm{NO}, \mathrm{NO}_{2}-\mathrm{H}_{2} \mathrm{O}, \mathrm{HNO}_{3}$ (Calculul debitelor şi concentraţiilor fluidelor din instalaţia de separare prin schimb izotopic $\mathrm{NO}, \mathrm{NO}_{2}-\mathrm{H}_{2} \mathrm{O}, \mathrm{HNO}_{3}$ ). In Proceedings of the National Congress of Chemistry (Congresul Naţional de Chimie), Volume I, Bucuresti, Romania, 11-14 September 1978; p. 50.

48. Igarashi, T.; Kambe, T.; Kihara, H. Industrial separation of oxygen isotopes by oxygen distillation. J. Label. Compd. Radiopharm. 2019, 62, 865-869. [CrossRef]

49. Orlov, A.; Ushakov, A.; Sovach, V. Mathematical modeling of nonstationary separation processes in gas centrifuge cascade for separation of multicomponent isotope mixtures. In Proceedings of the MATEC Web of Conferences; EDP Sciences: Amsterdam, The Netherlands, 2016; Volume 72, p. 01106.

50. Boca, M.L.; Ciortea, M.E. Aspects regarding at ${ }^{13} \mathrm{C}$ isotope separation column control using Petri nets system. IOP Conf. Ser. Mater. Sci. Eng. 2015, 95, 012122. [CrossRef]

51. Boca, M.L.; Secara, M. Analogy between mission critical detection in distributed systems and ${ }^{13} \mathrm{C}$ isotope separation column. Proc. SPIE 2015, 9258, 92582N.

52. Sas, D.M.; Secara, M. Preliminaries in numerical simulation of isotope separation open-loop processes. In Proceedings of the 13th International Conference on Engineering of Modern Electric Systems (EMES), Oradea, Romania, 11-12 June 2015; pp. 1-4.

53. Lai, C.K.; Lim, S.K.; Teh, P.C.; Yeap, K.H. Modeling Electrostatic Separation Process Using Artificial Neural Network (ANN). Procedia Comput. Sci. 2016, 91, 372-381. [CrossRef]

54. Bassam, A.; Conde-Gutierrez, R.A.; Castillo, J.; Laredo, G.; Hernandez, J.A. Direct neural network modeling for separation of linear and branched paraffins by adsorption process for gasoline octane number improvement. Fuel 2014, 124, 158-167. [CrossRef]

55. McBride, K.; Medina, E.I.S.; Sundmacher, K. Hybrid Semi-parametric Modeling in Separation Processes: A Review. Chem. Ing. Tech. 2020, 92, 842-855. [CrossRef]

56. Haykin, S. Neural Networks and Learning Machines, 3rd ed.; Pearson Education, Inc.: New York, NY, USA, 2009 ; pp. 818-845. 
57. Kuo, H.-F.; Faricha, A. Artificial Neural Network for Diffraction Based Overlay Measurement. IEEE Access 2016, 4, 7479-7486. [CrossRef]

58. Srinivasan, S.; Saghir, M.Z. Modeling of thermotransport phenomenon in metal alloys using artificial neural networks. Appl. Math. Model. 2013, 37, 2850-2869. [CrossRef]

59. Norgaard, M.; Ravn, O.; Poulsen, N.K.; Hansen, L.K. Neural Networks for Modelling and Control of Dynamics Systems; Springer London Ltd.: London, UK, 2000; pp. 13-114.

60. Valean, H. Neural Network for System Identification and Modelling. In Proceedings of the AQTR, Cluj-Napoca, Romania, 28-29 May 1996; pp. 263-268.

61. Chen, Y.; Ren, J.; Yi, C. Neural Networks for the Output Tracking-Control Problem of Nonlinear Strict-Feedback System. IEEE Access 2017, 5, 26257-26266. [CrossRef]

62. User Guide. Matlab (R2018a). Available online: https://www.mathworks.com/help/matlab/release-notes-R2018a.html\# responsive_o_canvas (accessed on 23 November 2021).

63. Aidinlou, H.R.; Nikbakht, A.M. Intelligent modeling of thermohydraulic behavior in solar air heaters with artificial neural networks. Neural Comput. Appl. 2019, 31, 3279-3293. [CrossRef]

64. Shrestha, A.; Mahmood, A. Review of Deep Learning Algorithms and Architectures. IEEE Access 2019, 7, 53040-53065. [CrossRef]

65. Hong, S.; Yang, H.; Zio, E.; Huang, N. A novel dynamics model of fault propagation and equilibrium analysis in complex dynamical communication network. Appl. Math. Comput. 2014, 247, 1021-1029. [CrossRef]

66. Bronshtein, I.N.; Semendyayev, K.A.; Musiol, G.; Muehlig, H. Handbook of Mathematics, 5th ed.; Springer: Berlin/Heidelberg, Germany, 2007; pp. 900-940.

67. Na, W.; Zhang, W.; Yan, S.; Feng, F.; Zhang, W.; Zhang, Y. Automated Neural Network Based Multiphysics Parametric Modeling of Microwave Components. IEEE Access 2019, 7, 141153-141160. [CrossRef]

68. Hong, S.; Yang, H.; Zhao, T.; Ma, X. Epidemic spreading model of complex dynamical network with the heterogeneity of nodes. Int. J. Syst. Sci. 2015, 47, 2745-2752.

69. Selvaraj, P.; Kwon, O.M.; Sakthivel, R. Disturbance and uncertainty rejection performance for fractional-order complex dynamical networks. Neural Netw. 2019, 112, 73-84. [CrossRef] [PubMed]

70. Chai, Z.; Yang, X.; Liu, Z.; Lei, Y.; Zheng, W.; Ji, M.; Zhao, J. Correlation Analysis-Based Neural Network Self-Organizing Genetic Evolutionary Algorithm. IEEE Access 2019, 7, 135099-135117. 